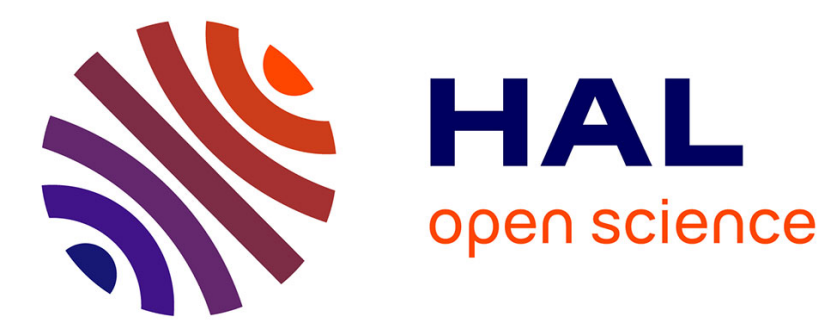

\title{
Wolbachia host shifts: routes, mechanisms, constraints and evolutionary consequences
}

Ehsan Sanaei, Sylvain Charlat, Jan Engelstädter

\section{To cite this version:}

Ehsan Sanaei, Sylvain Charlat, Jan Engelstädter. Wolbachia host shifts: routes, mechanisms, constraints and evolutionary consequences. Biological Reviews, 2020, 10.1111/brv.12663 . hal-03076872

\section{HAL Id: hal-03076872 \\ https://cnrs.hal.science/hal-03076872}

Submitted on 5 Jan 2021

HAL is a multi-disciplinary open access archive for the deposit and dissemination of scientific research documents, whether they are published or not. The documents may come from teaching and research institutions in France or abroad, or from public or private research centers.
L'archive ouverte pluridisciplinaire HAL, est destinée au dépôt et à la diffusion de documents scientifiques de niveau recherche, publiés ou non, émanant des établissements d'enseignement et de recherche français ou étrangers, des laboratoires publics ou privés. 


\section{Wolbachia host shifts: routes, mechanisms, constraints and evolutionary consequences}

Ehsan Sanaei ${ }^{1}$, Sylvain Charlat ${ }^{2}$ \& Jan Engelstädter ${ }^{1}$

${ }^{1}$ School of Biological Sciences, The University of Queensland, Brisbane, Australia

${ }^{2}$ Université de Lyon, Université Lyon 1, CNRS, UMR 5558, Laboratoire de

Biométrie et Biologie Evolutive, 43 boulevard du 11 novembre 1918, Villeurbanne F69622, France 


\section{Abstract}

Wolbachia is one of the most abundant endosymbionts on earth, with a wide distribution especially in arthropods. Effective maternal transmission and the induction of various phenotypes in their hosts are two key features of this bacterium. Here, we review our current understanding of another central aspect of Wolbachia's success: their ability to switch from one host species to another. We build on the proposal that Wolbachia host shifts occur in four main steps: 1) physical transfer to a new species, 2) proliferation within that host, 3) successful maternal transmission, and 4) spread within the host species. Host shift occasions can fail at each of these steps, and the likelihood of ultimate success is influenced by many factors. Some stem from Wolbachia properties (different strains have different abilities for host switching), others on host features such as genetic resemblance (e.g. host shifting is likely to be easier between closely related species), ecological connections (donor and recipient host need to interact with each other), or the resident microbiota. Host shifts have enabled Wolbachia to reach its enormous current incidence and global distribution among arthropods in an epidemiological process shaped by loss and acquisition events across host species. The ability of Wolbachia to transfer between species also forms the basis of ongoing endeavours to control pests and disease vectors, following artificial introduction into uninfected hosts such as mosquitoes. Throughout, we emphasise the many knowledge gaps in our understanding of Wolbachia host shifts, and question the effectiveness of current methodology to detect these events. We conclude by discussing an apparent paradox: how can Wolbachia maintain its ability to undergo host shifts given that its biology seems dominated by vertical transmission?

Keywords: Ecological connection, endosymbiont, host switching, host shift steps, horizontal transmission, transmission route, epidemiology, phylogenetics 


\section{Table of Contents}

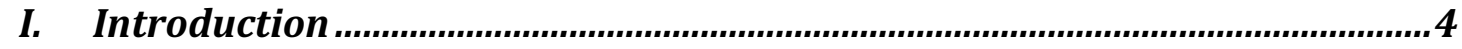

II. Steps involved in host shifts................................................................................

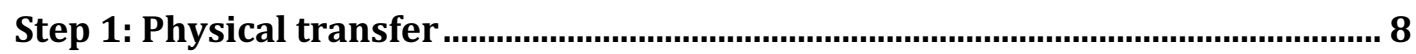

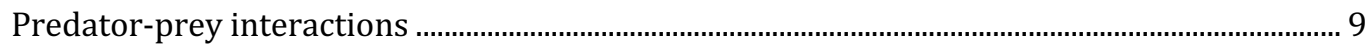

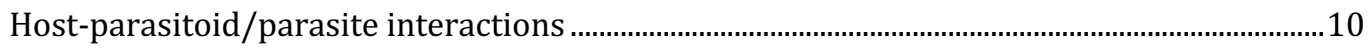

Shared plant and other food sources .............................................................................................11

Step 2: Survival and proliferation in the new host..................................................

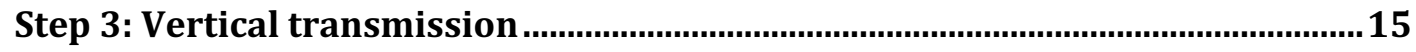

Step 4: Spread within the host population .......................................................16

III. Factors influencing host shifts............................................................. 19

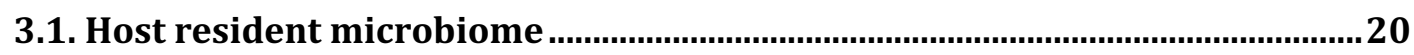

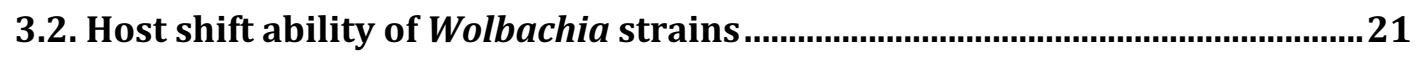

3.3. Genetic similarity of the donor and recipient hosts ......................................22

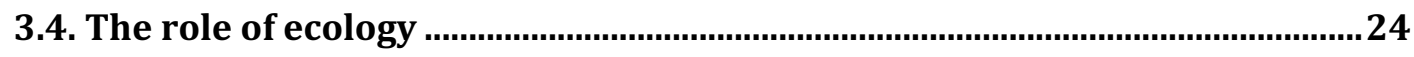

IV. Implications of Wolbachia host shifts........................................................ 26

4.1. Host shifts and between-host epidemiological dynamics...............................26

4.2. Host shifts and their reciprocal effect on Wolbachia genetic diversity..........28

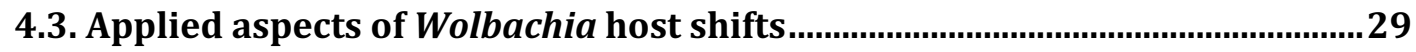

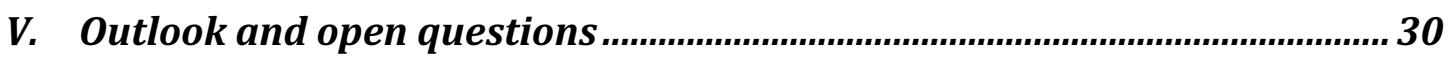

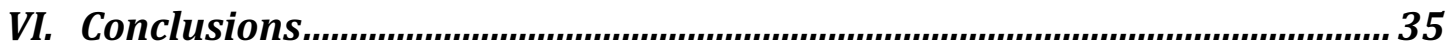

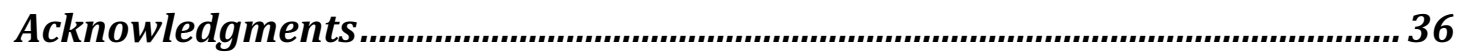

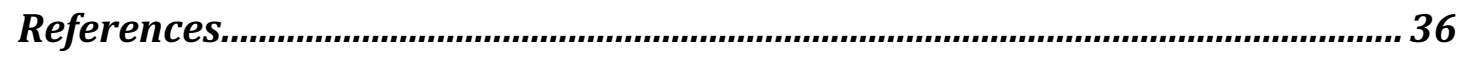




\section{Introduction}

The genus name Wolbachia denotes a diverse group of $\alpha$-proteobacteria that live as maternally inherited endosymbionts in many arthropods and nematodes (Hertig, 1936; Sironi et al., 1995). During the last decades, these bacteria have received much attention from researchers and the general public for three main reasons. First, they induce a wide range of fascinating phenotypes in their hosts, often detrimental and with wide-ranging evolutionary consequences (Charlat et al., 2003; Werren et al., 2008; Engelstädter \& Hurst, 2009). Second, Wolbachia is one of the most abundant symbionts, with around $50 \%$ of all arthropod species being infected (Hilgenboecker et al., 2008; Zug \& Hammerstein, 2012; Weinert et al., 2015; Bailly-Bechet et al., 2017). Finally, Wolbachia can be adopted as a controlling agent against vector-borne pathogens such as dengue, as well as pest species (Kambris et al., 2009; Iturbe-Ormaetxe et al., 2011; Asgari, 2017; Ross et al., 2019) .

The diversity of phenotypes induced by these bacteria include reproductive manipulations (Yen \& Barr, 1971; Rousset et al., 1992; Hurst et al., 2000), physiological and behavioural modifications (Min \& Benzer, 1997; Beltran-Bech \& Richard, 2014; Rohrscheib et al., 2015; Truitt et al., 2018; Bi \& Wang, 2020) and changes in their susceptibility to pathogens (Hedges et al., 2008; Teixeira et al., 2008; Kambris et al., 2009; Ekwudu et al., 2020). Wolbachia can also contribute to nutrient synthesis (e.g. Brownlie et al., 2009; Moriyama et al., 2015). Reproductive manipulations are common and take various forms. In cytoplasmic incompatibility (CI), Wolbachia induces embryonic death in the offspring of uninfected females mated with infected males. In the case of male killing, the bacteria cause the death of sons in the offspring of infected females. Finally, parthenogenesis and feminisation induction both stem from the transformation of potential males into females, which effectively leads to parthenogenesis in host species where zygotes can develop without mating.

From an evolutionary standpoint, these various effects can all be explained as adaptations enhancing the bacteria's fitness through that of the infected hosts, or more specifically the infected "matrilines", that is, the Wolbachia-carrying cytoplasmic lineages (Cosmides \& Tooby, 1981; Werren, 1997; Stouthamer et al., 1999). This reasoning is straightforward in the case of direct positive effects such as protection 
against pathogens or nutrients provision, but possibly less so when it comes to reproductive manipulations, where maternal (as opposed to biparental) transmission is the critical feature (Werren et al., 2008). In the case of CI, the relative fitness of infected embryos is only indirectly increased by the elevated death in the offspring of uninfected females mated with infected males (Hoffmann et al., 1990; O’Neill et al., 1997). Malekilling also has indirect fitness consequences in the sense that the death of infected females' sons does not immediately (and possibly not always) benefit their sisters: only reduced competition for food, or even consumption of their dead brothers, can generate some "fitness compensation" that will give an advantage to the infected cytoplasmic lineage (Hurst \& Majerus, 1993). Finally, in species where Wolbachia induces parthenogenesis or feminisation, its benefits are most evident and strong: in both cases, Wolbachia effectively turn sons into daughters, thus doubling its chances of transmission to the next generation.

Wolbachia have been reported in several major groups of terrestrial arthropods (hexapods, arachnids and isopods) as well as filarial nematodes (Taylor et al., 2005; Weinert et al., 2015). Not surprisingly given this high incidence and wide host range, the Wolbachia clade also exhibits a large genetic diversity. Within the only officially named Wolbachia species (Wolbachia pipientis), hundreds of molecularly distinct lineages, usually referred to as "strains" have been reported. They may be distinguished on the basis of single or multiple genetic markers, some of which have been proposed as standards in a "Multilocus Sequence Typing" scheme (MLST) (Baldo et al., 2006), providing informative (albeit incomplete) knowledge on divergence between Wolbachia lineages. These strains are distributed in several large clades denoted "supergroups", having likely diverged for over a hundred million years (Lo et al., 2002; Bordenstein \& Rosengaus, 2005; Glowska et al., 2015; Gerth \& Bleidorn, 2017; Lefoulon et al., 2020). On the basis of microbial taxonomy standards, these large groups could in principle take a species status, which is a matter of an ongoing debate (Ramírez-Puebla et al., 2015; Gerth, 2016; Lindsey et al., 2016; Bleidorn \& Gerth, 2018). Wolbachia strains falling in supergroups A and B, and to a lesser extent, F and E, are widely distributed across terrestrial arthropods, presumably mostly as reproductive parasites. Wolbachia from supergroups C and D are found in filarial nematodes where they are suggested as essential mutualists (Fenn \& Blaxter, 2004). The remaining supergroups are mostly limited to specific and smaller arthropod clades. 
How can such a high incidence, large host range and phylogenetic diversity be explained? The present-day distribution of any symbiont is driven by the interplay between processes that increase the number of carrier species and others that decrease it: co-speciation events and host shifts make to the first category while host extinction and symbiont losses form the second (e.g., Thompson, 1987; Charleston \& Perkins, 2006; Engelstädter \& Fortuna, 2019). Co-speciation occurs when symbionts are retained in both daughter lineages following a host speciation event, leading to symbiont divergence among host lineages (Hafner \& Nadler, 1990; de Vienne et al., 2013). (In what follows, we will equivalently use the term "co-divergence"; in this broad sense, "co-speciation" does not specifically imply that the daughter symbiotic lineages are attributed a "species" status.) Strict co-divergence of hosts and symbionts is expected to lead to congruent host and symbiont phylogenies, as indeed observed in a wide variety of symbiotic associations (Ashen \& Goff, 2000; Hosokawa et al., 2006; Thrall et al., 2007). Congruent phylogenies of Wolbachia and their hosts are also observed in nematodes (supergroup C and D Wolbachia) (Ferri et al., 2011; Bandi et al., 1998; Fenn \& Blaxter, 2004) and bedbugs (supergroup F) (Balvín et al., 2018), in accordance with the finding that the symbiont behaves as an obligate mutualist in these groups. By contrast, mirror phylogenies are much less common for the vast majority of other Wolbachia strains, indicating they often infect new species through host shifts, and also get lost.

Host shifts, also referred to as "horizontal transfers", are defined here as the transmission of a symbiont to a new host species that is successful at the population level, i.e. producing a new stable association. Early work on Wolbachia from A and B supergroups established that the phylogenies of the symbiont and its arthropod hosts are rarely congruent, ruling out the hypothesis that an ancestral Wolbachia infection underwent faithful co-speciation and strictly co-diversified with arthropods. Instead, these pioneering studies indicated that Wolbachia was subject to frequent host shift and extinction events (Schilthuizen \& Stouthamer, 1997; Meer et al., 1999; Bourtzis \& O’Neill, 1998; Werren et al., 1995; Heath et al., 1999; O’Neill et al., 1992; Rousset et al., 1992; Hurst et al., 1992). Moreover, in several studies, very closely related Wolbachia strains were detected in distantly related host species (from different genera to orders), suggesting that host shifts can cover large phylogenetic distances (Cordaux 
et al., 2001; Baldo et al., 2008; Noda et al., 2001; Stahlhut et al., 2010; Stouthamer et al., 1999). Evidence has accumulated since that the current distribution of Wolbachia is mostly governed by recent host shifts and infection losses (Bailly-Bechet et al., 2017). The host switching ability of Wolbachia has also been corroborated by the possibility to artificially transfer the bacteria across species through so-called "transinfection" experiments (reviewed in Hughes \& Rasgon 2014). Taken together, the available evidence indicates that Wolbachia has a great ability to move between host species (Huigens et al., 2004a; Cordaux et al., 2001; Heath et al., 1999; Sintupachee et al., 2006; Baldo et al., 2008; Russell, 2012).

A special case of host shifting arises when Wolbachia enters a new species via hybridisation. Limited gene flow (introgression) between closely related species through the production of hybrids is a common phenomenon (Mallet, 2005). Wolbachia strains inducing bidirectional CI (embryonic death of hybrids caused by two incompatible Wolbachia strains) may contribute to reproductive isolation and thus foster speciation (Bordenstein et al., 2001). But hybridisation may also facilitate the passage of Wolbachia if only one of the populations is infected. Following mating between an infected female from species A and an uninfected male from species B, maternal transmission the symbiont and recurrent backcrossing to B males may lead to Wolbachia introgression into species B, especially if the symbiont carries its own driving force through reproductive manipulations or fitness benefits (Rousset \& Solignac, 1995; Raychoudhury et al., 2009; Turelli et al., 2018). Hybridisationmediated host shifts have been suggested in the Nasonia species complex (Raychoudhury et al., 2009), Acraea, Hypolimnas and Eurema butterflies (Jiggins, 2003; Charlat et al., 2009; Miyata et al., 2020), in the grasshopper Chorthippus parallelus (Martínez-Rodríguez \& Bella, 2018) as well as in Drosophila species (Turelli et al., 2018; Cooper et al., 2019).

Host shifts though introgression are peculiar for a number of reasons. In contrast to genuine horizontal transfer, introgression occurs by regular maternal inheritance, that is, through vertical transmission. As a result, the mitochondrial haplotype associated with Wolbachia in the donor species spreads along with the symbiont into the recipient species. Such events therefore leave a signature of incongruency between nuclear and mitochondrial evolutionary histories, in terms of divergence time or even tree topology, 
but no incongruence between the Wolbachia and mitochondrial trees. For example, in the butterfly genus Hypolimnas, a shared infected mitochondrial haplotype has been observed in two different species, indicating a case of introgression that would not have been identified on the basis of Wolbachia and mtDNA data alone, that is, without prior knowledge on the species boundaries (Charlat et al., 2009; Sahoo et al., 2018). Hybridisation-mediated host shifts also represent a special case in that their rates of success are expected to be much higher than that of other transfer routes. This is because introgression releases the bacteria from the challenges of facing an extracellular environment and having to find their way to the germ line. Moreover, as discussed below, the high genetic similarity between the donor and recipient species means that the long-term maintenance of the new infection is also more likely. Host shifts by introgression may thus be more common than genuine host shifts via horizontal transfer, but it should be emphasized that they cannot be seen as a general explanation for the wide distribution of Wolbachia, considering that genetically similar Wolbachia strains are often observed in phylogenetically distant hosts. For this reason, in what follows, we will focus our discussion on host shifts mediated by horizontal transmission in a strict sense, excluding the special case of hybridisation.

\section{Steps involved in host shifts}

It is useful to conceptionally break down the process of host-shifting into several distinct steps (Combes, 2001; Woolhouse et al., 2005; Bright \& Bulgheresi, 2010), an approach that has previously been suggested for Wolbachia (Vavre et al., 2003; Riegler et al., 2004). Here, we put forward the following four steps: 1) physical transfer of the bacteria to a female of a new species, 2) proliferation within this new individual host, 3) successful maternal transmission to its offspring, and 4) spread within the new host population. Each of these steps presents its own challenges that may or may not be overcome, depending on both host and bacterial factors, as summarised in Figure 1.

\section{Step 1: Physical transfer}

This very first step may take place via a vector or directly, with more or less prolonged exposure to the external environment (Breeuwer \& Jacobs, 1996; Baldo et al., 2008; Cordaux et al., 2001; Heath et al., 1999). As Wolbachia is adapted to the intracellular lifestyle, facing the environment may constitute a critical challenge (reviewed by Sicard 
et.al., 2014). Below we discuss four routes identified as plausible, among an obviously immense set of ecological possibilities.

\section{Predator-prey interactions}

Virtually any living organism is part of a prey-predator interaction, and arthropods are no exception to that rule (Hassell, 1978; Sabelis, 1992). In principle, predators may receive a new Wolbachia infection from their prey, an hypothesis that has sometimes been put forward to explain the sharing of similar infections in preys and predators (Kittayapong et al., 2003; Enigl \& Schausberger, 2007; Wiwatanaratanabutr \& Zhang, 2016). A few cases of direct experimental evidence for successful Wolbachia transmission from prey to predator have also been reported (e.g., between woodlice (Le Clec'h et al., 2013)).

Although the majority of insects harbour various bacteria in their gut as part of their microbiome (Engel \& Moran, 2013; Dillon \& Dillon, 2004), the lumen secretions can be strong enough to digest prey cells and their intracellular bacteria (Dow, 1987; Terra, 1990; Terra \& Ferreira, 2012). Therefore, there is a challenge for Wolbachia to first survive in the lumen, and then to enter the host tissue through the gut epithelium (Sicard et al., 2014). Hosts with an already established Wolbachia infection sometimes also harbour these bacteria in their gut lumen, indicating some ability of Wolbachia to overcome the first of these challenges (Cheng et al., 2000; Ye et al., 2017; Osborne et al., 2012; Kikuchi \& Fukatsu, 2003; Andersen et al., 2012). Predaceous mites that consume infected phytophagous mites have been reported as Wolbachia positive (by PCR) for up to 48 hours (Johanowicz \& Hoy, 1996; Enigl et al., 2005) and on rare occasions, the infection was shown to become established in the new host (Johanowicz \& Hoy, 1996). Therefore, it appears that Wolbachia can somehow and sometimes escape the initial digestion in the midgut.

How often is Wolbachia transferred to a new host species through predation? Surveys provide little evidence for shared Wolbachia infections in predators and their hosts and therefore limited support for this route of transfer (Cordaux et al., 2001; Enigl et al., 2005; Yun et al., 2011; Hurst et al., 2012). For example, in a screening of mosquitos and their natural predators in China and Thailand, no cases of Wolbachia strains shared between prey and predators were reported (Wiwatanaratanabutr \& Zhang, 2016). 
Moreover, if predation-mediated transfers were common, one would expect that, all else being equal, predator taxa such as spiders may exhibit a higher Wolbachia incidence than other groups, which does not seem to be the case (Rowley et al., 2004; Baldo et al., 2007; Wang et al., 2010; Yun et al., 2011; Bailly-Bechet et al., 2017). Wolbachia host shifts per se were also not found to occur more frequently in spiders than in other arthropod orders (Bailly-Bechet et al., 2017). A recent study indicated that most of the microbiome of spider preys can be found in the gut of their predators, although the presence of Wolbachia in the spiders themselves was rarely observed (Kennedy et al., 2020). Thus, although some arthropods predators are presented with ample opportunities to acquire Wolbachia from their prey, such transfers do not seem to occur frequently.

\section{Host-parasitoid/parasite interactions}

Parasitoids comprise around $20 \%-25 \%$ of all insect species and most terrestrial arthropods can be parasitised by one or several of them (Godfray, 1994; Mills, 2009). In theory, all parasitic strategies, including castration, parasitoidism, micropredation (feeding on a host individual without killing it, e.g. in mosquitos) and phoresis (attaching to a host individual for transportation), may expose both sides to microbial exchange. Moreover, compared to prey-predator interactions, the physical association between host and parasite individuals typically lasts longer, occurs at various developmental stages, and directly puts Wolbachia in contact with a wide variety of tissues, and not just the gut lumen). All of these features may increase the probability of parasitism-mediated host shifts. Not surprisingly therefore, these pervasive ecological interactions have been found to open a door for horizontal transfer, notably in the case of Wolbachia and host-parasitoid interactions (Cook \& Butcher, 1999; Heath et al., 1999; Vavre et al., 1999; Hunter et al., 2003; Kittayapong et al., 2003; Huigens et al., 2004b; Raychoudhury et al., 2009; Kageyama et al., 2010; Morrow et al., 2014; Ahmed et al., 2015; Klopfstein et al., 2018; Hou et al., 2020).

In contrast to prey-predator interactions, the direction of Wolbachia exchange can also be from the parasite to its host, at least when it is not always lethal (Vavre et al., 1999). When a parasite and its host are infected with the same strain, understanding the direction of the transfer can be challenging. One strategy can be to assess the presence of close Wolbachia relatives in close host relatives on either side. Unless infections 
have been recently acquired in the donor, or subject to a recent sweep, larger diversity and shared infection with sister groups are expected on the donor side (Johannesen, 2017).

Complex infection routes may exist between parasites and hosts. A single common parasitoid species can be a source of infection for multiple shared hosts (Dedeine et al., 2005; Noda et al., 2001) or a single host may be a source of infection for multiple parasites. For example, natural inter- and intraspecific horizontal transfers of parthenogenesis-inducing Wolbachia have been reported between Trichogramma parasitoid wasps sharing host eggs (Huigens et al., 2000). Parasites may also play a vector role between infected and uninfected host without themselves being infected. In support of this notion, Ahmed et al. (2015) reported that the mouthparts and ovipositors of an Aphelinid parasitoid become contaminated with Wolbachia when this wasp feeds on Wolbachia-infected Bemisia tabaci, which in turn can be a source of infection for the next parasitised host.

In summary, parasitic interactions may well be one of the most common routes of Wolbachia host shifts. If this is the case, we would predict that hosts attacked by diverse parasites and, reversely, generalist parasites, should display a high Wolbachia incidence. Some results suggest such a trend may hold (Kittayapong et al., 2003; Klopfstein et al., 2018), but this prediction remains to be thoroughly tested.

\section{Shared plant and other food sources}

Shared food sources create important ecological links between species within a community (Paine, 1980) and may constitute a route of transmission for microbes that can survive either within or on the surface of the food. Plants are one of the best examples of such an ecological platform (Chrostek et al., 2017). Wolbachia has been found in the salivary glands of several herbivore and non-herbivore insects (Dobson et al., 1999). By physical contact between arthropod mouthparts and plant tissue, their bacteria may be transferred to the plants. The ability of Wolbachia to tolerate an extracellular environment was demonstrated in cell-free medium (Schneider's medium), where the $w$ AlbB strain could survive for up to 7 days (Rasgon et al., 2006). Some strains of Wolbachia may have the ability to survive within plants for even longer 
time, during which they may be transferred to new hosts (Burke et al., 2020). In a recent study, one strain has been reported to survive in cotton leaf phloem vessels for up to 50 days, retaining the potential to infect whiteflies (Li et al., 2017a). Similarly, the high abundance of Wolbachia in pollen and broods of a carpenter bee (Ceratina calcarata) (McFrederick \& Rehan, 2016), and the existence of identical Wolbachia strains in a hoverfly species (Merodon luteihumerus) and its host plant's bulb tissue (sea squill) suggested plants as a plausible platform for Wolbachia transmission in this system (Zorić et al., 2019). As a result of plant-mediated host shifts, taxonomically diverse arthropod species feeding on the same plants may share common or closely related Wolbachia strains, as has been reported for the agricultural setting of a pumpkin farm (Sintupachee et al., 2006). Sharing a common host plant may also explain high host shift rates among various species of fig wasps (Shoemaker et al., 2002; Haine \& Cook, 2005; Yang et al., 2013). Horizontal transmission via plant tissue is not limited to Wolbachia. A study focusing on Rickettsia showed that transmission of this symbiont from a cotton plant to whiteflies was plausible (Li et al., 2017b). It is also suggested that Cardinium can survive in both artificial food and plant tissues and thereby infect leafhoppers (Gonella et al., 2015).

Insect food sources that may mediate Wolbachia host shifts are not restricted to plants. In fungus growing ants, fungal gardens represent a likely source of Wolbachia horizontal transmission between the ants and their social parasites (Tolley et al., 2019). The transfer of food between ants and crickets inhabiting their nests through trophallaxis appears to have mediated some Wolbachia host shifts (Tseng et al., 2020). Sharing the same dung patches may also have led to Wolbachia shifts between two Malagasy dung beetle species (Miraldo \& Duplouy, 2019). Ingestion of corpses may also lead to horizontal transmission within or between species. For example, laboratory experiments showed that Tyrophagus putrescentiae mites can transfer their Wolbachia infection to corpses of Drosophila, which are later ingested by Drosophila larvae, which results in the establishment of a new infection (Brown \& Lloyd, 2015).

\section{Step 2: Survival and proliferation in the new host}

Before reaching the germline cells and undergoing successful vertical transmission, Wolbachia first have to survive in their new environment. The host's intra and extracellular immunity is an inevitable part of the arthropod's physiology, one that 
usually prevents infections by any invading microbe (Zug \& Hammerstein, 2015). How can Wolbachia survive such a threat and proliferate in the new host?

Once a bacterium colonises a new arthropod host, the immune system is often triggered by specific pathogen-associated molecular patterns (PAMPs) such as peptidoglycans (Zaidman-Rémy et al., 2006; Otten et al., 2018). These may then activate the innate immune responses which are categorized into cellular and humoral types (Salt \& Salt, 1970; Boman \& Hultmark, 1987; Lavine \& Strand, 2002). The transcription of antimicrobial peptides such as Defensin was indeed observed in Aedes aegypti following transinfection with $w$ AlbB (Bian et al., 2010), wMel (Kambris et al., 2009) and wMelPop-CLA (Rancès et al., 2012), which usually leads to Wolbachia titre reduction or complete loss of the bacteria. However, in some Wolbachia transinfection studies, expression of the major host antibacterial immunity genes was only slightly altered or not changed at all (Bourtzis et al., 2000; Chevalier et al., 2012). One plausible explanation is that Wolbachia have a unique functional peptidoglycan amidase $\left(\mathrm{AmiD}^{\mathrm{wol}}\right)$ that cleaves its own bacterial cell wall so that it may remain hidden from both humoral and cellular immune responses (Eleftherianos et al., 2013; Wilmes et al., 2017; Otten et al., 2018). Indeed, this has been suggested as a potential explanation for the higher incidence of Wolbachia than that of other symbionts such as Cardinium and Rickettsia, in arthropods that do mount immune responses to Gram negative bacteria, but not in groups that lack components of the gram negative innate immune pathway, such as some Hemiptera and Acari (Waxman et al., 2014; Morand et al., 2015; Weinert et al., 2015). In addition, the absence of $\mathrm{AmiD}^{\text {wol }}$ in mutualist Wolbachia strains of nematodes is in line with the hypothesis that the evolution of $\mathrm{AmiD}^{\mathrm{wol}}$ may be causally linked to the host shifting ability in Wolbachia supergroups A and B (Wilmes et al., 2017).

However, Wolbachia's ability to modify its own cell wall may not be sufficient to prevent detection of the bacteria in all situations. Besides the peptidoglycans, cell-tocell movements of Wolbachia (probably based on the activation of cell phagocytic and clathrin/dynamin-dependent endocytic machinery (White et al., 2017)) can cause oxidative stress to the host and consequently lead to a diverse regulation of immunerelated genes (Caragata et al., 2017). Wolbachia shows a feature that can be interpreted as another layer of defence against this threat: similar to other $\alpha$-proteobacteria that are 
facultative symbionts (such as Brucella and Anaplasma), Wolbachia is always observed in the host cell within a triple layer vacuole, that can partly protect it from cellular immune responses (reviewed in Sicard et al., (2014)). Such a mechanical shield provides a basic protection against the host immune response.

Even though Wolbachia may often escape general immune responses from the host, we would expect resistance against the bacteria to be selected for in many systems (Koehncke et al., 2009; Hornett et al., 2010; Salunkhe et al., 2014) because of the direct or indirect negative fitness effects often associated with the infection (Fleury et al., 2000; Koehncke et al., 2009; Le Clec'h et al., 2012; Charlat et al., 2003). There are no high-rank taxonomic groups of terrestrial arthropods where extensive screening has failed to identify any infected species. (One possible exception to that rule is the order Phasmatodea (stick insects), where 247 individuals from 29 species have been screened for Wolbachia without a single positive specimen (Werren \& Windsor, 2000; Weeks et al., 2003; Perez Ruiz et al., 2015).) A possible interpretation of this pattern is that no single general resistance mechanism ever evolved. Alternatively, it may be that Wolbachia infections do not always constitute a significant and negative selective pressure. Some control strategies have however been reported that are specific to particular host or Wolbachia lineages (reviewed by López-Madrigal \& Duarte (2019). Transinfection experiments indicate that different host species usually have different immune reactions or physiological response against similar Wolbachia strains (Rancès et al., 2012; Herbert \& McGraw, 2018). Conversely, a given host usually does not react in the same way to all Wolbachia strains (e.g. the different immune response of $A$. aegypti or Lutzomyia longipalpis to wMel and wMelPop-CLA strains (Rancès et al., 2012; da Silva Gonçalves et al., 2019)). In response to the severity of the Wolbachia fitness cost, such strain-specific host reactions can be selected in a very short evolutionary time scale ( $\mathrm{Li}$ et al., 2018). For example, a comparative study of the Nasonia species complex led to the identification of a Wolbachia density suppressor $(W d s)$ gene in $N$. vitripennis that tends to decrease the titre of the native $w$ VitA strain and consequently its vertical transmission (Funkhouser-Jones and van Opstal et al. 2018). It appears that this strain-specific controlling strategy has evolved through the change of only a single amino acid in $W d s$ (Funkhouser-Jones and van Opstal et al. 2018). 


\section{Step 3: Vertical transmission}

Effective transmission of the infection to the host's offspring requires reaching the germ line cells and being maintained in the zygote. This ability of Wolbachia to initiate vertical transmission may arise from its tropism toward somatic stem cells niche, that the bacteria may first occupy as a stable reservoir before reaching the germline itself (Frydman et al., 2006). Toomey et al., (2013) showed that the high concentration of Wolbachia in the somatic stem cells is not only a key factor for vertical transmission but also a conserved feature observed in diverse strains of various Drosophila species. From the somatic stem cells, Wolbachia may utilize the host's vitellogenin transovarial transportation system to enter the oocyte (Guo et al., 2018). Regulation of such transportation routes or any other mechanisms to control the Wolbachia transmission to the oocyte may constitute evolved host adaptations to control the Wolbachia titre in Nasonia vitripennis (Funkhouser-Jones and van Opstal et al 2018) and Armadillidium vulgare (Rigaud \& Juchault, 1992; Cordaux et al., 2011). Once the bacteria have successfully entered the zygote, they need to reach important host tissues (including but not limited to the germ line stem cells) without disrupting the embryo's development. This may be achieved through the utilisation of the host cytoskeleton, which appears to be achieved by bundling of Wolbachia protein WD0830 to host actin filaments (Newton et al., 2015; Sheehan et al., 2016) as well as by increasing the division rate of germ line stem cells (Fast et al., 2011) to localize and enhance their titre (for details see (Pietri et al., 2016; Guo et al., 2019; Landmann, 2019)).

How often do Wolbachia fail at the transmission step of the host shift process? Some light can be shed on this question by transinfection studies again, although it is often difficult to distinguish between failure to proliferate and failure to be transmitted (i.e., steps 2 vs 3). Most reported transinfection attempts resulted in an infection that was stable over many generations (reviewed by Hughes and Rasgon, (2014)) indicating that, at least under these artificial conditions involving high initial Wolbachia titres, transmission rates in a new host can be high. However, these data almost certainly involve a publication bias, both towards successful transinfection outcomes and towards transinfection attempts between closely related donor and recipient host species (see below for a discussion of the phylogenetic distance effect). Several studies also reported inefficient transmission and/or loss of Wolbachia after a few generations. For example, (Clancy \& Hoffmann, 1997) achieved successful transinfection of a 
Wolbachia strain from $D$. simulans to D. serrata but transmission rate was low ( $\sim 90 \%)$. Rigaud et al., (2001) reported similar transmission rates following transinfection of Wolbachia between two closely related woodlice species and very low ones $(<10 \%)$ between more distantly related woodlice species. Artificial transfer of a double Wolbachia infection from the cherry fruit fly Rhagoletis cerasi to D. simulans led to the loss of one strain from the first generation, and inefficient vertical transmission of the other (Charlat et al., 2004; Riegler et al., 2004). Finally, transinfection of Wolbachia from a parasitoid wasp to $D$. simulans was successful but transmission rates were also low and the infection was lost by the seventh generation (Meer \& Stouthamer, 1999). These results lead us to think that under natural conditions, where initial infection titres must be much lower than in most transinfection experiments, and where transferred Wolbachia strains will often come from more distantly related hosts, efficient maternal transmission constitutes a challenging step in Wolbachia host shifts.

\section{Step 4: Spread within the host population}

Without inducing a phenotype driving its spread, Wolbachia may easily become lost from a new host species. This is because maternal transmission itself does not entail any epidemiological drive: in the absence of positive fitness effects on its host, Wolbachia would not be expected to increase in frequency. Even with perfect transmission fidelity Wolbachia would just be equivalent to a neutral new allele, with limited chances of spreading. Deleterious fitness effects and imperfect transmission pose further restrictions on the spread of Wolbachia within a population. Invasion of a new population thus likely stems from specific phenotypic effects, including reproductive manipulations in the first place (such as $\mathrm{CI}$, feminisation, male killing and parthenogenesis), and/or providing direct fitness benefits to their female hosts (e.g. synthetising nutrients, or perhaps more commonly, protect against pathogens) (Werren, 1997; Stouthamer et al., 1999; Fenton et al., 2011; Zug \& Hammerstein, 2014). Moreover, the intensity of the induced phenotypes and consequently the strength of drive needs to be strong enough to enable spread (Breeuwer \& Werren, 1993; Unckless et al., 2009; Koga et al., 2012; Osborne et al., 2012).

Although we know little about how often these conditions are met following natural host shifts, transinfection experiments can again be informative. These have shown that Wolbachia may sometimes retain its original phenotypic effects upon transfer into a new host, sometimes induce a different phenotype, and sometimes have no detectable 
effect at all. For example, four distantly related strains (wRi, wAlbA, wAlbB, and wPip) and three close relatives (from the wMel group), that all induced CI in their original host, also induced CI upon introduction in A. aegypti (reviewed in Sicard et al., 2019). A strain inducing male-killing in its original host (the moth Cadra cautella) induced CI instead in a novel host (the moth Ephestia kuehniella) (Sasaki et al., 2002). The wInn strain, inducing male killing in its original host (D. innubila) (Dyer \& Jaenike, 2004) had no observable phenotype (either CI or male killing) in transinfected D. simulans and D. melanogaster (Veneti et al., 2012). The Hypolimnas bolina butterfly is also informative with regard to phenotypic switches: host suppression of male-killing revealed the ability of the same Wolbachia strain to also induce CI in this species (Hornett et al., 2008). No obvious patterns regarding these changes in phenotypes, e.g. a tendency to preferentially change from one particular phenotype to another, have been uncovered yet. For more examples, including examples where the strength of CI changed in either direction upon transinfection, we refer to (Poinsot et al., 1998; Hughes \& Rasgon, 2014; Hoffmann et al., 2015; Ross et al., 2019).

Among all reproductive manipulations, CI is probably the most prevalent Wolbachiaassociated phenotype and may thus often contribute to its establishment in a host population. Here, in the simplest case, infected females have a relative reproductive advantage due to the embryonic death of uninfected individuals fertilised by infected males. This advantage is said to be "positive frequency-dependent", because it increases as infected males become more frequent in the population. Upon arrival of CI-inducing Wolbachia in a new host species, the bacteria are likely to exhibit imperfect maternal transmission and may often have negative effects on host fitness. In such a scenario, theory predicts, and experimental studies have confirmed, that there will be an invasion threshold frequency below which Wolbachia is lost from the population and above which it should spread to a high and stable prevalence (Fine, 1978; Hoffmann et al., 1990; Turelli \& Hoffmann, 1995; Xi et al., 2005; Hancock et al., 2016; Kriesner et al., 2016). The invasion threshold depends on the strength of CI, the fitness cost or benefits associated with Wolbachia and the fidelity of vertical transmission (Turelli, 1994; Rasgon \& Scott, 2004; Li \& Wan, 2019). For example, in the A. aegypti system where Wolbachia has been artificially introduced, a 20-30\% invasion threshold has been estimated (Axford et al., 2016; Turelli \& Barton, 2017). 
In release programs of Wolbachia infected individuals, the threshold can be artificially overcome by increasing the number of infected hosts in each release (Hoffmann et al., 2011). But how can Wolbachia tackle this obstacle in nature? One possibility is that Wolbachia passes the invasion threshold in (locally) small populations where a new infection would represent a substantial proportion of the population and random genetic drift may facilitate Wolbachia establishment (Turelli, 1994; Jansen et al., 2008). As mentioned above, another possibility is that Wolbachia may provide direct fitness benefits such as provisioning of nutrients (Nikoh et al., 2014; Brownlie et al., 2009; Douglas, 2009; Hosokawa et al., 2010; Darby et al., 2012; Ju et al., 2020), or protection against pathogens (Fenton et al., 2011). Models of Wolbachia inducing both CI and fitness benefits predict rapid spread and fixation of Wolbachia even when starting from very low initial frequencies, provided that the maternal transmission rate is sufficiently high (Dobson et al., 2004; Fenton et al., 2011; Zug \& Hammerstein, 2018). However, the beneficial effects of Wolbachia can often depend on environmental conditions (Reynolds et al., 2003; Mouton et al., 2006; Zug \& Hammerstein, 2014). Moreover, beneficial effects observed in long-established associations may not have been present initially. This view is supported by the finding that the $w \mathrm{Ri}$ strain in Drosophila simulans evolved from imposing reduced to increased fecundity in infected females over a time span of 20 years (Weeks et al., 2007). 


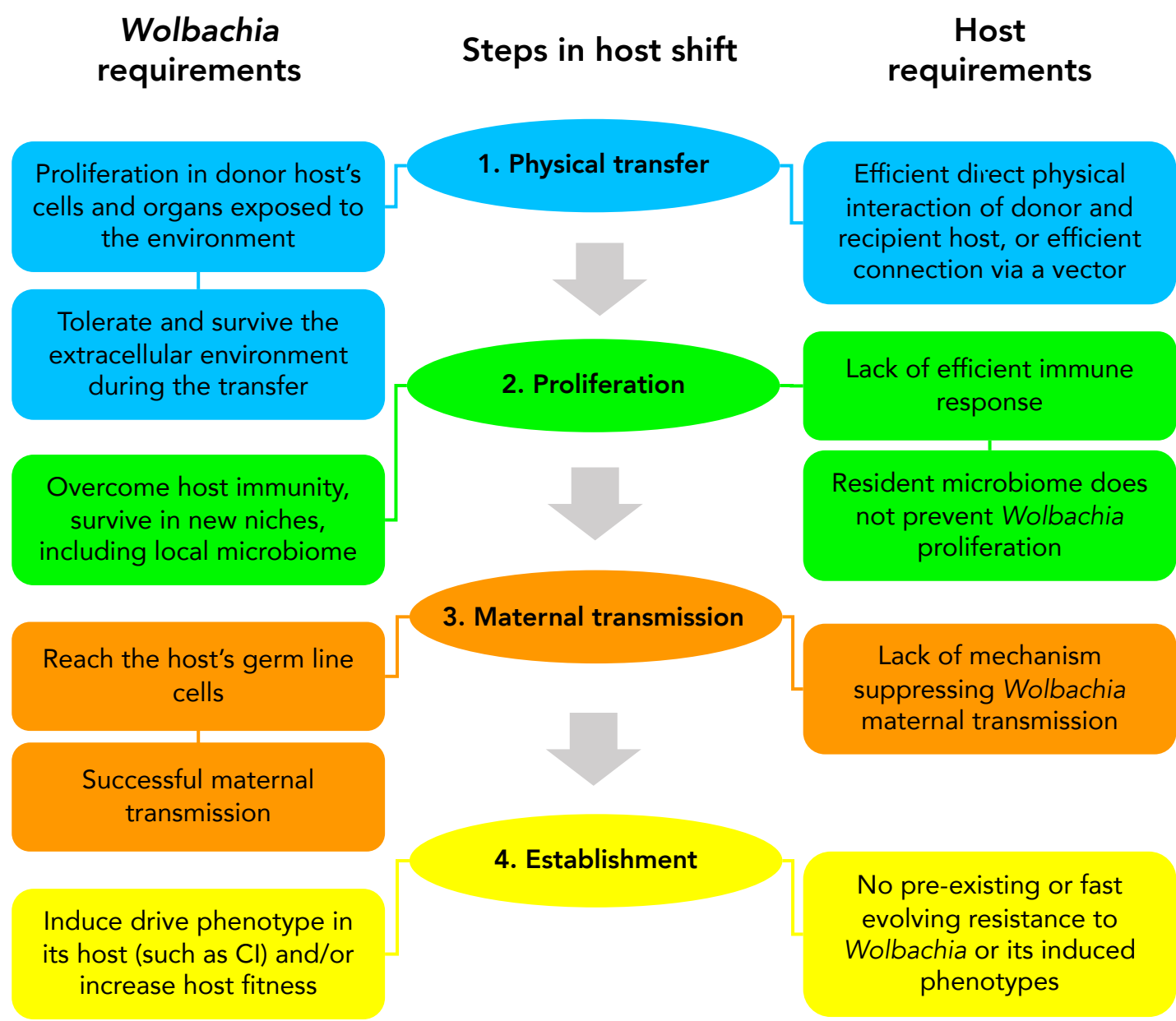

Figure 1: Wolbachia and host requirements in each steps of the host shift process.

\section{Factors influencing host shifts}

Why does a particular Wolbachia strain succeed in switching from host A to B, but not to C? Or why does Wolbachia $w \mathrm{~A}$ often switch while $w \mathrm{~B}$ does not? We will discuss four main factors influencing host shifts: Wolbachia interactions with the host's resident microbiome, variation between different strains in their ability to undergo host shifts, genetic similarity between donor and recipient host, and finally, ecological conditions. 


\subsection{Host resident microbiome}

Interactions between Wolbachia and the host's resident microbiome, including exploitative competition for shared resources (Caragata et al., 2013), triggering of host immunity against competitors (Pan et al., 2012; Joubert et al., 2016) or even collaboration, can critically impact the Wolbachia titre (Vorburger \& Perlman, 2018; Duan et al., 2020). The microbiome may thus influence the last three steps in the host shift process, from Wolbachia proliferation to maternal transmission and withinpopulation establishment (Zouache et al., 2009; Chandler et al., 2011; Hughes et al., 2014; Dittmer \& Bouchon, 2018; McLean et al., 2018; Fromont et al., 2019). In extreme cases, such interactions may completely prevent the host shift. For example, the native microbiome of Anopheles mosquitos has been reported to block Wolbachia maternal transmission (Hughes et al., 2014). Wolbachia-microbe interactions are not always a restrictive factor and may even facilitate Wolbachia establishment, for example through increased host fitness, such as those induced by co-infections of Wolbachia and Spiroplasma in a spider mite (Xie et al., 2019) and co-infections of Wolbachia and Cardinium in Hylyphantes graminicola spider (Li et al., 2020), or through strengthened reproduction manipulations, as seen in a spider mite where the expression of Cardinium-induced CI is strengthen by Wolbachia (Zhu et al., 2012) or in a in whitefly where Cardinium-Wolbachia coinfections enhance male-killing (Lv et al., 2020).

A special but common case arises when the recipient host species is already infected with a different strain of Wolbachia. Two scenarios are then conceivable. First, the new variant may enter the new host population as a single infection, that is, in an initially uninfected individual host. In this case there will be a direct competition within the host population between the resident and invader Wolbachia matrilines. In the absence of direct fitness benefits, mathematical models indicate that if the resident strain induces any reproductive manipulation, and especially if the two strains induce bidirectional CI, this should inhibit invasion of the new strain (Rousset et al., 1991; Engelstädter et al., 2004; Telschow et al., 2005). If the invasion of the new strain is nevertheless successful, this is generally expected to lead to extinction of the resident strain rather than a stable polymorphism (Rousset et al., 1991; Engelstädter et al., 2004), unless there is a pronounced host population structure (Keeling et al., 2003). An empirical example for such a displacement is provided by the recent spread of the CI-inducing $w \mathrm{Ri}$ variant in eastern Australia which was accompanied by a marked decline in the frequency of 
the $w$ Au strain that was initially very prevalent in this region although it does not appear to induce any reproductive manipulation (Kriesner et al., 2013). The second scenario is when the new Wolbachia arises in an originally infected host, thus producing a double infection at the individual level. In this case, theory predicts that competition at the population level is less severe and the new strain can spread to form a stable polymorphism with the old strain so that host individuals with either both strains or none may co-occur, although double infections should dominate (Frank, 1998; Engelstädter et al., 2004). Such instances of coinfections with different Wolbachia strains are indeed commonly observed in arthropods (e.g. Perrot-Minnot et al., 1996; Kondo et al., 2002).

\subsection{Host shift ability of Wolbachia strains}

Transinfection studies as well as surveys of natural arthropod populations indicate that the ability to undergo host shifts varies widely across Wolbachia lineages. Some strains, especially from supergroups $\mathrm{C}, \mathrm{D}$ and $\mathrm{F}$ that comprise obligate symbionts, appear to be characterised by very low host shift rates (Balvín et al., 2018). On the other side of the spectrum, some "superspreaders" have been identified, especially within supergroups A and B. These include strains labelled as ST41 in Lepidoptera (Ilinsky \& Kosterin, 2017), wRi in Drosophila (Turelli et al., 2018) and HVR-2 in Acromyrmex ants (Tolley et al., 2019). Their enhanced host shift ability is indicated by a high number of host species resulting from numerous transfer events in the recent past. For example, it has been estimated that the $w$ Ri-like strains spread across eight Drosophila species within the last 14,000 years, probably through a mixture of introgression and horizontal transfer in a strict sense (Turelli et al., 2018).

What drives such differences in host shift ability remains largely unknown. It may be that fast evolving genomic regions, such as those associated with mobile elements, contribute to the ability of some strains to rapidly adapt to new hosts. As genomic data accumulate, systematic analyses of genomic variation affecting traits involved in the Wolbachia / host interactions, such as sensing, signalling and secretion may help resolve this issue (Lindsey, 2020). Wolbachia variations affecting host tissue niche tropism and localisation may also be at play. While the existence of some strains in specific tissues seems related in the first place to their phenotypic effects (Sapountzis et al., 2015; Douglas, 2009), Wolbachia localisation in host somatic cells and in the 
extracellular environment also affects horizontal transmission (Sicard et al., 2014). For example, the high density of Wolbachia in the gut of leaf cutting ants (Andersen et al., 2012) and consequently in their faeces may facilitate intra-species horizontal transmission via trophallaxis behaviour (Frost et al., 2014), and at the same time also boost host shifts. Another example of a plausible link between somatic localisation and horizontal transmission is the proliferation in haemocytes that facilitate rapid transportation to organs exposed to the outside environment, such as the gut and salivary glands (Frost et al., 2014; Braquart-Varnier et al., 2015; Le Clec'h et al., 2017). However, such interpretations of tissue tropisms variations remain speculative at this stage. In particular, it is generally unclear how much tissue distribution will affect host shift abilities, relative to other potential factors, including those related to immune evasion, or the robust induction of reproductive manipulations and other phenotypes across many host species.

\subsection{Genetic similarity of the donor and recipient hosts}

It is expected that closely related host species are alike in many respects, including their intra- and extracellular environments and immunity (Perlman \& Jaenike, 2003; Gilbert \& Webb, 2007; Longdon et al., 2011). A symbiont would thus be expected to switch most easily between close relatives (Charleston \& Robertson, 2002; Clayton et al., 2003; Tinsley \& Majerus, 2007). This expectation, sometimes referred to as the "phylogenetic distance effect" (PDE) (Longdon et al., 2011; Engelstädter \& Fortuna, 2019), may be applicable to any entity undergoing host shifts, from transposable elements (Peccoud et al., 2017; Reiss et al., 2019) to Wolbachia (Jiggins et al., 2002; Engelstädter \& Hurst, 2006; Baldo et al., 2008; Russell et al., 2009).

The existence and strength of the PDE has been investigated both experimentally (through transinfections) and through the comparative analysis of Wolbachia and hosts phylogenies. A review of 25 transinfection studies indicated a positive correlation between success rates and relatedness of donor and recipient hosts (Russell et al., 2009). Comparative phylogenetic studies have been less conclusive. Russel et al., (2009) reported a signal indicative of a PDE separately in a group of ants and butterflies. Several host-shifts events among closely related species, as inferred from patterns of Wolbachia strain distributions on host phylogenies, support the PDE hypothesis, e.g. in weevils (Lachowska et al., 2010; Sanaei et al., 2019), Trissolcus wasps (Guz et al., 
2012), and Drosophila (Haine et al., 2005; Turelli et al., 2018). In contrast, in some case studies focused on certain arthropod families or genera, only a negligible part of the data, if any, appeared to indicate a PDE, e.g. in fig wasps (Shoemaker et al., 2002), fungus growing ants (Frost et al., 2010), lepidopterans (Ahmed et al., 2016) and bees (Gerth et al., 2013). Although the PDE may play an important part in explaining the distribution of Wolbachia and its host shifts, evaluating its impact is not an easy task. Large and well-resolved trees are required, on both the Wolbachia and host sides and rigorous statistical methods need to be applied, that quantify the effect of host relatedness on host-shifts. To date, this has been achieved in other host-parasite systems (e. g. Faria et al., (2013), but not for Wolbachia. The interpretation of a PDE is further complicated by the possibility that host phylogenies may correlate not only with physiological but also with ecological features: higher rates of transfers between closely related host species may also stem from niche similarities such as shared food, predators or parasitoids (see following section). It may thus be difficult to tease apart physiological and ecological effects. For example, in the case of Wolbachia host shifts among fig wasp species, the importance of the PDE compared to the ecological interactions in the syconium community is not clear (Yang et al., 2012)), and the latter should be taken into account in phylogenetic analyses.

Just as closely related hosts may be similarly permissive to Wolbachia, they may share features making them more reluctant to hosting new infections, for example because of phylogenetic inertia in resistance to particular Wolbachia strains, or in phenotypic suppression (Longdon et al., 2011; Waxman et al., 2014). For example, Culex quinquefasciatus and C. pipiens were suggested to control Wolbachia density in their gonads in the same way, through a possibly shared ancestral mechanism (Emerson \& Glaser, 2017). But such a pattern may not always hold. For example, in the wasp Nasonia vitripennis, the $W d s$ protein appears to inhibit maternal transmission of the $w$ VitA Wolbachia strain, possibly by blocking its passage from nurse cells to oocytes (Funkhouser-Jones and van Opstal et al. 2018). This seems to stem from a recent amino acid substitution in this gene, since no such phenomenon is seen in the close relative Nasonia giraulti (Funkhouser-Jones and van Opstal et al. 2018). Male killing suppression in $H$. bolina butterflies offers another example of a derived and recent mechanism, stemming in that case from one or more mutations in a single host genomic region (Reynolds et al., 2019). These studies indicate that rather than being polygenic 
and conserved ancestral traits, host resistance may often be strain- and host-specific control systems that evolved very recently, and with a simple genetic basis. Such mechanisms, especially if they are costly, may also be relatively short-lived, just as Wolbachia infections themselves, as discussed below. The rapid degradation of such control traits following Wolbachia losses may also explain the apparent absence of large Wolbachia-resistant host clades.

\subsection{The role of ecology}

Besides resemblance stemming from phylogenetic relatedness, shared ecological features, even extrinsic ones such as climate, may partially explain the current distribution of intracellular microbes (Woodhams et al., 2020). Occupying the same ecological niche by definition enhances interactions between species, e.g. through direct physical contact, shared food, predators or parasitoids. It is therefore not surprising that Wolbachia host shifts can be observed between species living in the same habitat, be they closely related or not (Kittayapong et al., 2003; Morrow et al., 2014). For instance, in a particular intertidal ecosystem, two distantly related amphipod species were reported to share the same Wolbachia strain (Cordaux et al., 2001). In another study, host ecology (mycophagy vs. non-mycophagy) was predictive of relatedness between different supergroup A Wolbachia strains detected in mushroomassociated dipterans, whereas host phylogenetic relatedness was not (Stahlhut et al., 2010).

The presence of shared strains in two host species with significant niche overlap could be explained by frequent physical contact. An alternative but not mutually exclusive explanation could be that host shifts are facilitated because Wolbachia's own niche is aligned with that of their hosts. Although the cellular environment may seem in part disconnected from the host's extracellular physiology and open-environment ecological conditions, many intracellular microorganisms exhibit a level of niche preference oriented to their preferred ecosystem (Isberg et al., 2009; Mertens \& Samuel, 2012). For instance, aphids with similar but geographically separated environmental niches tend to harbour closely related bacterial symbionts (Henry et al., 2013). Wolbachia strains may also have their own preferential niche (Lemoine et al., 2020). Versace et al., (2014) monitored the infection frequencies of different Wolbachia strains in D. melanogaster laboratory lines flies subject to hot and cold experimental 
environments over 1.5 years. They demonstrated that two strains exhibited reduced fitness in cold temperatures and became lost after 15 generations, whilst the frequency of another increased by $50 \%$. Moreover, the results were reproduced when the hotadapted Drosophila lines were moved again to cold environments. These results indicate that different strains react differently to temperature and thus have different niche preferences. Such associations between Wolbachia strains and environmental features may also be detectable in natural systems. For example, several studies indicate that Wolbachia density and prevalence in herbivorous arthropods depends on host plants (Ahmed et al., 2010; Toju \& Fukatsu, 2011; Guidolin \& Cônsoli, 2017). Similarly, some strains are observed at higher infection frequency in higher temperature areas of their host range (Mouton et al., 2006; Toju \& Fukatsu, 2011; Zhu et al., 2018). A recent meta-analysis reported complex relationships between climatic conditions and Wolbachia prevalence in arthropods, without a clear general trend: while a weak positive relationship between Wolbachia incidence and temperature was observed in temperate regions, prevalence was generally lower in the tropics (Charlesworth et al., 2019). Strain specific effects may explain some of this complex pattern.

Host niches may thus impact possibilities of Wolbachia host shifts, but the bacteria may also, reciprocally, affect host niches. Many mutualistic endosymbionts can limit their host's niche (Corbin et al., 2017; Perlmutter \& Bordenstein, 2020), e.g. by reducing thermal tolerance, as has been reported in Buchnera endosymbionts in aphids (Zhang et al., 2019)). This phenomenon may also be at play in hosts where Wolbachia is required for survival (e.g. a group of Wolbachia strains from supergroup F in bed bugs (Hosokawa et al., 2010)). In other cases, Wolbachia may extend their hosts' niche, e.g. by providing protection against pathogens. Finally, and in line with its other manipulative capabilities, Wolbachia may modify hosts' ecological preferences toward its own (Lemoine et al., 2020). For example, under laboratory conditions, infected $D$. melanogaster preferred cooler temperature than uninfected flies, which is possibly an indication that Wolbachia manipulated its host's thermal preference (Truitt et al., 2018). 


\section{Implications of Wolbachia host shifts}

\subsection{Host shifts and between-host epidemiological dynamics}

Wolbachia-host co-diversification processes may be considered within a standard epidemiological framework where host species represent individuals, host shifts correspond to transmission events and Wolbachia extinction to host recovery. This view makes it clear that the current high global frequency of Wolbachia in arthropods is the result of a balance between gain and loss events, that is, between host shifts and Wolbachia extinction (Werren \& Windsor, 2000). In technical terms, for Wolbachia to spread and be maintained within arthropods or any more specific clade, its basic reproductive number $R_{0}$ - here, the number of successful host shifts achieved by a Wolbachia strain (in an otherwise uninfected clade of hosts) before it goes extinct needs to exceed one. For example, a simple deterministic model assuming a cycle of susceptible, infected, recovered and susceptible host species (SIRS model) predicts that $R_{0}$ is given by the ratio between the rates of host shifts and extinctions (Keeling \& Rohani, 2011). Zug et al., (2012) also considered a stochastic model in which host shifts occur on small-world networks, designed to capture the expectation that host shifts take place preferentially between closely related hosts (i.e. the PDE), but also occasionally between distantly related host. Epidemiological models explicitly including host trees and the PDE have also been constructed (Engelstädter \& Hurst, 2006; Engelstädter \& Fortuna, 2019). Amongst other predictions, these models suggest that species-rich host clades, especially those resulting from recent adaptive radiations, should exhibit a greater incidence of Wolbachia infections than more evolutionary inert, species-poor host clades. At least when using taxonomy as a proxy for phylogenetic relationships, this hypothesis does not seem to be supported by data on Wolbachia infection incidence (Weinert et al., 2015).

Building on this epidemiological framework, some studies have aimed at estimating the critical parameters underlying the current Wolbachia distribution. Early large scale surveys have indicated similar incidence in different regions of the globe (Werren et al., 1995; Werren \& Windsor, 2000). This pattern suggests that Wolbachia may have reached a steady state, i.e. an epidemiological equilibrium between loss and acquisition rates, the relative values of which may be inferred from the observed global incidence (Zug et al., 2012). More recently, loss and acquisitions rates were independently 
estimated from a large-scale comparison between Wolbachia and host mitochondrial phylogenies, used to infer likely scenarios of loss and acquisition (Bailly-Bechet et al., 2017). This study suggested that uninfected species acquire Wolbachia once every 9 million years on average, whilst infected species lose Wolbachia every $\sim 7$ million years. These numbers would translate into a global incidence of about $40 \%$, which happens to match the observed global incidence in this data set. This concordance fits the hypothesis that Wolbachia has indeed reached a global equilibrium, in line with the geographical stability of its incidence.

Let us keep in mind that these take-home numbers, based on the only attempt made so far to estimate these epidemiological parameters, should be considered with caution, for a number of reasons. On purely technical grounds, uncertainties in the host and symbiont phylogenies, inferred in both cases from single molecular markers, translate into uncertainties in the loss / acquisition scenarios and thus in the estimated rates. In addition, multiple infections have been neglected in this study, which may introduce some bias if strains found in multiple infections tend to follow a peculiar epidemiology. The fact that Wolbachia may sometimes recombine at high rates (Bonneau et al., 2018) also introduces the possibility that only some genomic portions, and not entire Wolbachia lineages, may be concerned with some of the inferred loss / acquisition events. Variations in loss and acquisition rates between host clades also mean that perhaps no single clade follows the average trend estimated from the entire dataset. Finally, and most critically, these estimations may in part be confounded by difficulties in assessing which events, out of all losses and acquisitions visible on the host tree, correspond to genuine species-level versus mere individual level events (e.g. transient infections acquired from the environment, or loss of infection from one mother to its offspring) that were filtered out in this study, making the rates inferred possibly too conservative (Bailly-Bechet et al., 2017).

Overall, these various sources of uncertainty and potential errors may help explain the apparent discrepancy between these global estimates of Wolbachia host shift rates and some recent reports indicating that many Drosophila species have acquired new Wolbachia infections within the last few thousand years (Turelli et al., 2018; Cooper et al., 2019). It may be that the species group of Drosophila investigated in these studies acquire infections much more frequently than the average arthropod species does, or 
that the particular Wolbachia strains studied are more prone to host shifts than the average Wolbachia strain. It may also be that the average arthropod acquires Wolbachia more often than suggested by the conservative approach of Bailly-Bechet et al. (2017). Also notable is the fact that the above-mentioned acquisition rate estimations exclude introgression, and only consider horizontal transfers in a strict sense (jumps between distinct cytoplasmic lineages) as acquisition events. More studies, focused on particular clades, are needed to resolve this complex issue.

\subsection{Host shifts and their reciprocal effect on Wolbachia genetic diversity}

Wolbachia exhibits a wide phenotypic diversity but also, at the genomic level, a high degree of instability, stemming from recurrent rearrangements, recombination events, and integrations or losses of mobile elements, that occur at a surprisingly high rate for an intracellular symbiont (Gerth \& Bleidorn, 2017). This feature may be understood in relation with Wolbachia's ability to undergo host shifts. Wolbachia strains in arthropods tend to harbour larger genomes than in nematode hosts, albeit with substantial variation (Fenn \& Blaxter, 2006; Nikoh et al., 2014). This includes diversified mobile elements such as bacteriophages and transposons (Ishmael et al., 2009; Kent \& Bordenstein, 2010; Leclercq et al., 2011; Reveillaud et al., 2019; Bing et al., 2020). Although these mobile elements may be generally costly for Wolbachia on a short time-scale, as they usually are for any organism, their presence may fuel genomic instability. In that sense, they may be essential in generating the raw heritable variations underlying the evolution of the many phenotypes that Wolbachia displays, including its ability to survive in a new host (Licht, 2018). Reciprocally, host shifts may also boost Wolbachia genetic diversity by exposing diverse lineages to diverse new environments, that is, diverse selective constraints (Frank, 1997; Read \& Taylor, 2001). Host shifts may also contribute to Wolbachia genomic variations in a more proximate manner, by generating co-infections by several Wolbachia strains, that are indeed of commune occurrence (Perrot-Minnot et al., 1996; Kondo et al., 2002) and open the possibility of recombination, occurring between both close and distant Wolbachia lineages (Jiggins Francis M. et al., 2001; Werren \& Bartos, 2001; Jiggins, 2002; Baldo et al., 2006; Atyame et al., 2011; Ellegaard et al., 2013). Recombination produces genetic novelty on its own (Klasson et al., 2009; Ilinsky \& Kosterin, 2017; Tolley et al., 2019) but also maintains a selective pressure on mobile elements for transposition, 
in a positive evolutionary feedback loop that may boost genetic diversification in the long run.

\subsection{Applied aspects of Wolbachia host shifts}

There is an ongoing interest in utilizing Wolbachia in many applications such as pest management and vector borne disease control (Townson, 2002; Zabalou et al., 2004; Floate et al., 2006; Vavre \& Charlat, 2012; Ritchie et al., 2015, 2018; Berec et al., 2016; Nikolouli et al., 2018; Liu \& Guo, 2019). These approaches often involve an artificial host shift by transinfection of Wolbachia to new host species. Probably the most prominent example is the successful introduction of dengue-virus suppressing Wolbachia into A. aegypti mosquitos in ten countries (O’Neill, 2018). A better understanding of natural host shifts may both help implement these efforts and also assess and possibly mitigate their inherent risks (Yen \& Failloux, 2020). For example, Wolbachia strains with a high host shifting ability may be avoided in such projects, to reduce the risks of spreading infections in non-targeted species, although they may also settle more easily in the targeted one and thus be seen as good candidates in the first place. We currently do not have a general picture of what Wolbachia strains should be seen as such "superspreaders", if only because of the small fraction Wolbachia's diversity that has been sampled so far (Detcharoen et al., 2019), and we also do not know what genomic features provide them with such a property. Reciprocally, artificial releases may provide a mean to investigate the dynamics of natural host shifts (Ross et al., 2019). For example, releasing and monitoring the spread of $A$. aegypti infected with CI-inducing strain in Queensland (Australia) provided an opportunity to study its progress and establishment (Hoffmann et al., 2011; Axford et al., 2016). This has highlighted the critical effect of environmental heterogeneity on Wolbachia invasion dynamics (Schmidt et al., 2017).

The spread of new infections following host shifts from artificially infected species may have important consequences, including a reduction in host genetic diversity, altered population dynamics and sex ratios and possibly even extinction (Charlat et al., 2003; Engelstädter \& Hurst, 2009). Some have argued that in the absence of a thorough understanding of potential onward host shifts of Wolbachia and their consequences, these risks should preclude widespread application of Wolbachia for disease control (Loreto \& Wallau, 2016). However, given that Wolbachia already have a high global 
incidence, with $40-50 \%$ of all arthropod species being infected, any species is likely to be naturally exposed to many new Wolbachia infections. The additional risk of new infections caused by human Wolbachia release programs has therefore been argued to be negligible, especially in the case of releasing infected male mosquitos (Dobson et al., 2016).

\section{Outlook and open questions}

The complexity of Wolbachia host shifting encompasses the gamut of biology, ranging from molecular genetics, physiology and immunology to ecology, epidemiology and evolutionary biology. As has become clear in the preceding sections, our understanding of this complexity is still in its infancy. For example, while Wolbachia surveys suggest that sharing a common parasitoid appears to be a frequent route of transfer, many other routes are plausible and could be more important in particular host groups. Similarly, although we have good data on the process of Wolbachia establishment within a population following an artificial release, we know little about the equivalent process following natural host shifts (e.g. how can a new CI-inducing strain overcome the invasion threshold?). Various factors have been identified that may facilitate or hinder host shifts, including ecological and genetical similarity between donor and recipient hosts, but we are largely ignorant about their relative importance. We are also only beginning to understand the long-term dynamics of Wolbachia spread across whole clades of host species.

At a quantitative level, we know even less. Building upon the conceptual model of a host shift comprising four consecutive steps, we can partition the probability that such an event effectively occurs into four individual probabilities, $P_{1}$ to $P_{4}$ (corresponding to steps 1 to 4 in Figure 2). A long-term and ambitious goal would be to estimate these probabilities and how they depend on host and Wolbachia groups as well as other factors. At present, we can only suspect that $P_{3}$ and $P_{4}$ are lower than $P_{1}$ and $P_{2}$, i.e. that vertical transmission and spread in the population likely represent stronger limitations than physical transfer and proliferation, but there is no hard data to corroborate this conjecture. Although different types of experiments and comparative studies shed some light on these issues, they all come with limitations. Estimating $P_{1}$ is 
very hard and has rarely been attempted (but see Rigaud \& Juchault (1995). Transinfection experiments can be seen as addressing $P_{2}$ and, in many cases where several host generations were included, may also provide information pertaining to $P_{3}$. However, the presumably large initial titre used in these experiments means they can only be used to estimate upper limits for $P_{2}$ and $P_{3} . P_{4}$ can be addressed by field or cage population studies in which few infected individuals are released, but given its presumably low value, it seems virtually impossible to directly estimate $P_{4}$ from natural situations where Wolbachia needs to spread from a single infected female through a large population. Detailed stochastic models (Jansen et al., 2008) combined with good estimates for parameters such as the transmission rate, strength of CI and host effective population size therefore seem indispensable for this step.

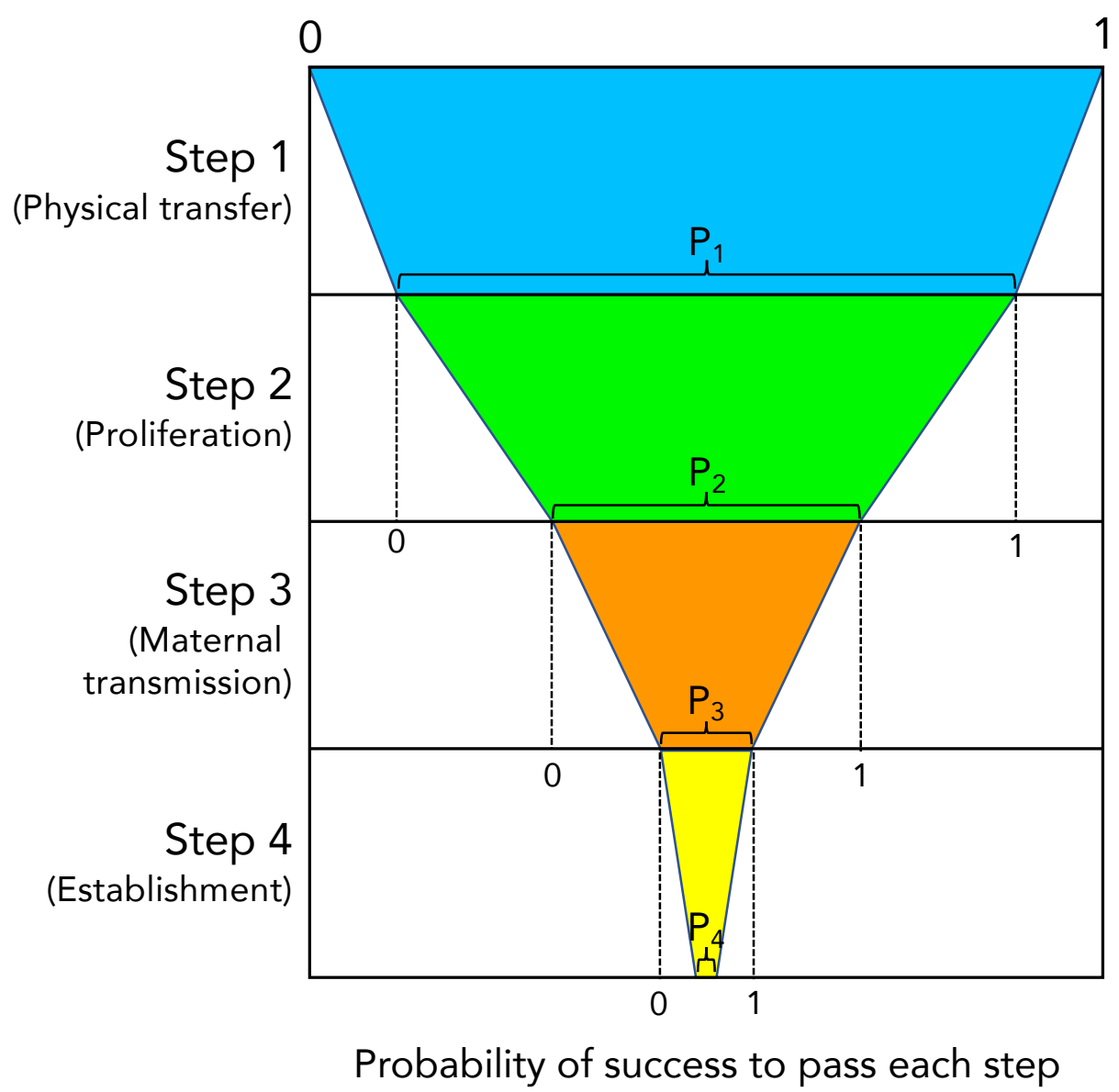

Figure 2. Breaking host shifts into successive events, with various respective probabilities of occurrence. Each step $i$ in the process is associated with a probability $P_{i}$ that it is successfully taken by Wolbachia. Graphically, each probability is represented by the bottom width of the respective trapezoid relative to its top width. 
Under this framework, the total probability that a host shift occurs is given by the product of the four individual probabilities, $P_{\text {total }}=\prod_{i} P_{i}$, graphically represented by the bottom width of the final, yellow trapezoid, relative to the total width. 
Comparative studies estimating host shift rates from phylogenetic trees (e.g., BaillyBechet et al., (2017)) can be seen as addressing the total probability $\left(\prod_{i} P_{i}\right.$, per unit of time) of successful host shifts, but cannot disentangle the probabilities for the individual steps. However, when powered by sufficiently large and robust trees (ideally built from whole genome sequencing data, as argued below), such comparative studies have considerable potential to estimate not only average host shift rates but uncover variation in these rates between Wolbachia strains, host groups or ecosystems.

In order to fill some of the mentioned knowledge gaps, some of the methodologies commonly used in past Wolbachia research may require revisions. Putative host shifts are often identified through the detection of very similar Wolbachia strains in two different host species via PCR and sequencing of one or a small number of genes. While informative in many regards, this approach also suffers from at least two caveats. First, the presence of Wolbachia genes in DNA extracted from a host (detectable by PCR methods) does not necessarily indicate a stable infection in that host (Chrostek \& Gerth, 2019). It could merely indicate the presence of Wolbachia (or even just Wolbachia DNA) on the surface or in the gut of the specimen, or the presence of a truly intracellular but transient infection. This common approach is therefore unable to distinguish between genuine host shifts and either contaminations or unsuccessful spillovers of Wolbachia into other species, where not all four steps have been successful. For unequivocal identifications of host shifts, it remains to be determined if Wolbachia is indeed established via vertical transmission in both the hypothesised donor and recipient host and has spread to significant prevalence. Potential improvements of screening methodologies may include the detection of Wolbachia within host cells through microscopy, sampling from many individuals within a population rather than relying on one or a few, and ideally rearing of individuals in the lab in order to ascertain whether the infection is stably transmitted maternally to the next generation (Chrostek $\&$ Gerth, 2019). This integrative approach is obviously not achievable in large surveys and comparative studies, but may usefully complement them in more targeted studies.

The second problem is how to determine the direction of a host shift, and whether it occurred directly between two species or through some intermediates. The identification of the same Wolbachia strain in two different host species often represents only two visible spots in the otherwise obscure, large and entangled networks of past and extent hosts and symbionts lineages. The simplest scenario of a direct host 
shift between the two species under focus may be misleading. To obtain a more complete picture, one strategy is to increase the number of sampled species within a closed or semi-closed environment (e.g. Bailly-Bechet et al., 2017). But such large scale studies have revealed that often many distinct host lineages carry strains that cannot be distinguished on the basis of one or even a few genes such as those included in the Wolbachia MLST scheme (Bleidorn \& Gerth, 2018). This lack of phylogenetic signal can certainly be resolved by deeper sequencing that can reveal genomic variation among strains that previously looked virtually identical (Atyame et al., 2011; Bleidorn \& Gerth, 2018). When utilized on both the host and Wolbachia side, whole genome sequencing approaches can provide highly informative details on the evolutionary histories of all players, including the cytoplasmic host genomes, offering detailed information on the likely direction, timing and mode (hybridisation vs. horizontal transfer) of past host shifts (e.g. Turelli et al., (2018), Cooper et al., (2019)).

A puzzling open question that we have not explicitly discussed yet concerns the evolutionary conservation of the Wolbachia traits required for successful host shifts. These events being usually regarded as rare, we would expect that the Wolbachia genes involved (e.g., those allowing movement from the gut lumen into host cells, or controlling somatic stem cell niche tropism) to either decay neutrally after transfer events or even be selected against if they are costly. Frequent horizontal transmission within species may represent a source of purifying selection on such traits, and may thus contribute to their evolutionary conservation (Hurst \& McVean, 1996). Indeed, through several of the transfer routes discussed here, such as shared parasitoids, predators or food sources, horizontal transmission within species is expected to be much more common than transmission between species. A recent study on the horizontal transmission of Wolbachia in a spider indicated indeed that intra-species transmission (by cannibalism or social interactions) is more likely to occur than interspecies transmission (by predation or parasitism) (Su et al., 2019). On the other hand, strong association of particular host mitochondrial haplotypes with Wolbachia, as reported in several studies, argues against frequent horizontal transmission within species (e.g. wRi strain in D. simulans (Hale \& Hoffmann, 1990; Turelli et al., 2018), $w$ Bollb in H. bolina (Charlat et al., 2009) and $w \mathrm{Mel}$ in D. melanogaster (Richardson et al., 2012)). The genes involved in host shifts may also be maintained as functional through pleiotropic effects, that is, if they also play significant roles in within-host 
Wolbachia dynamics. For example, cell to cell movement of Wolbachia involves shifts between different tissues or organs, that is, between contrasting environments (Sicard et al., 2014). The physiological plasticity of Wolbachia, required for survival in diverse host cell niches, may also maintain in these bacteria some features required in host shifting. Finally, it may be that host shifts in themselves select for those Wolbachia lineages that have retained this capacity. The plausibility of this 'clade selection' hypothesis (Williams, 1992; Hurst \& McVean, 1996) will depend on the frequency of host-shift events, and may seem unlikely in the light of the above-mentioned estimates in the order of millions of years (Bailly-Bechet et al., 2017). Notwithstanding the possibility that host shift rates may in fact be more frequent in many parts of the Wolbachia tree, it is notable that if jumps into new hosts represent the only way out of extinction, even rare events may constitute a critical and possibly effective selective force.

\section{Conclusions}

1. The ability to undergo host shifts is a critical feature of Wolbachia, with significant effects on the global incidence and distribution of these bacteria, their genetic diversity, and evolutionary consequences for their arthropod hosts. Evidence for this comes from phylogenetic studies, many successful transinfection experiments where Wolbachia has been transferred to a new host, and direct observations of host shifts in experimental settings.

2. Host-shifts can be conceptualized as taking place in four steps: physical transfer to a new host, proliferation within the new host, vertical (maternal) transmission, and establishment in the new population. Physical transfer can potentially occur via a number of routes, of which parasites/parasitoids and shared food sources appear the most plausible. All steps come with their own challenges and requirements from both host and Wolbachia that determine whether a host shift is successful.

3. There are many factors that influence the likelihood of successful host shifts of Wolbachia to a new host. The resident microbiome of the recipient host plays a large role, including other pre-existing Wolbachia strains, as well as different maternally inherited endosymbionts or other microbes. Different strains of 
Wolbachia appear to have a different propensity to undergo host shifts, and the probability of host shifts appears to decline with increasing phylogenetic distance between donor and recipient host. Finally, ecological conditions are important, both for ensuring physical contact (direct or indirect) to the new host and, potentially, for providing a suitable niche for Wolbachia to thrive in.

4. In the long term, the dynamics of Wolbachia host-shifts and losses across many host species can be considered from an epidemiological perspective. Cophylogenetic studies of Wolbachia and their hosts can be used to understand these dynamics and estimate the rates of Wolbachia host shifts and extinction events. However, this requires large, well-resolved and robust phylogenetic trees, and we therefore only have a very incomplete understanding of these parameters.

5. Studying natural host shifts can be useful for the application of Wolbachia to vector born disease or pest control strategies, for example by identifying strains that can easily switch between hosts ("super-spreaders"). Reciprocally, Wolbachia release programs represent a welcome opportunity to study the initial spread and early evolutionary dynamics of Wolbachia within a new host species.

\section{Acknowledgments}

We thank Sassan Asgari, Lyn Cook, Michael Gerth, Karyn Johnson, Ben Longdon, Mathieu Sicard, Lucy Weinert, Roman Zug and two anonymous reviewers for providing valuable comments on the manuscript.

\section{References}

Ahmed M.Z., Breinholt J.W. \& Kawahara A.Y. 2016. Evidence for common horizontal transmission of Wolbachia among butterflies and moths. BMC Evol. Biol. 16: 118. 
Ahmed M.Z., Li S.-J., Xue X., Yin X.-J., Ren S.-X., Jiggins F.M., Greeff J.M. \& Qiu B.-L. 2015. The intracellular bacterium Wolbachia uses parasitoid wasps as phoretic vectors for efficient horizontal transmission. PLoS Pathog. 11: e1004672.

Ahmed M.Z., Ren S.-X., Mandour N.S., Greeff J.M. \& Qiu B.-L. 2010. Prevalence of Wolbachia Supergroups A and B in Bemisia tabaci (Hemiptera: Aleyrodidae) and Some of Its Natural Enemies. J. Econ. Entomol. 103: 1848-1859.

Andersen S.B., Boye M., Nash D.R. \& Boomsma J.J. 2012. Dynamic Wolbachia prevalence in Acromyrmex leaf-cutting ants: potential for a nutritional symbiosis. J. Evol. Biol. 25: 1340-1350.

Asgari S. 2017. Chapter 10 - Host-Microbe Interactions: A Case for Wolbachia Dialogue. pp. 173-183. In: Wikel S.K., Aksoy S., \& Dimopoulos G. (eds), Arthropod Vector: Controller of Disease Transmission, Volume 1, Academic Press, Elsevier Inc.

Ashen J.B. \& Goff L.J. 2000. Molecular and Ecological Evidence for Species Specificity and Coevolution in a Group of Marine Algal-Bacterial Symbioses. Appl. Environ. Microbiol. 66: 3024-3030.

Atyame C.M., Delsuc F., Pasteur N., Weill M. \& Duron O. 2011. Diversification of Wolbachia Endosymbiont in the Culex pipiens Mosquito. Mol. Biol. Evol. 28: 2761-2772.

Axford J.K., Ross P.A., Yeap H.L., Callahan A.G. \& Hoffmann A.A. 2016. Fitness of wAlbB Wolbachia Infection in Aedes aegypti: Parameter Estimates in an Outcrossed Background and Potential for Population Invasion. Am. J. Trop. Med. Hyg. 94: 507-516.

Bailly-Bechet M., Martins-Simões P., Szöllősi G.J., Mialdea G., Sagot M.-F. \& Charlat S. 2017. How Long Does Wolbachia Remain on Board?. Mol. Biol. Evol. 34: 1183-1193.

Baldo L., Ayoub N.A., Hayashi C.Y., Russell J.A., Stahlhut J.K. \& Werren J.H. 2008. Insight into the routes of Wolbachia invasion: high levels of horizontal 
transfer in the spider genus Agelenopsis revealed by Wolbachia strain and mitochondrial DNA diversity. Mol. Ecol. 17: 557-569.

Baldo L., Hotopp J.C.D., Jolley K.A., Bordenstein S.R., Biber S.A., Choudhury R.R., Hayashi C., Maiden M.C., Tettelin H. \& Werren J.H. 2006. Multilocus sequence typing system for the endosymbiont Wolbachia pipientis. Appl. Environ. Microbiol. 72: 7098-7110.

Baldo L., Prendini L., Corthals A. \& Werren J.H. 2007. Wolbachia Are Present in Southern African Scorpions and Cluster with Supergroup F. Curr. Microbiol. 55: $367-373$.

Balvín O., Roth S., Talbot B. \& Reinhardt K. 2018. Co-speciation in bedbug Wolbachia parallel the pattern in nematode hosts. Sci. Rep. 8: 8797.

Bandi C., Anderson T.J.C., Genchi C. \& Blaxter M.L. 1998. Phylogeny of Wolbachia in filarial nematodes. Proc. R. Soc. Lond. B Biol. Sci. 265: 2407-2413.

Beltran-Bech S. \& Richard F.-J. 2014. Impact of infection on mate choice. Anim. Behav. 90: 159-170.

Berec L., Maxin D. \& Bernhauerová V. 2016. Male-killing bacteria as agents of insect pest control. J. Appl. Ecol. 53: 1270-1279.

Bi J. \& Wang Y.-F. 2020. The effect of the endosymbiont Wolbachia on the behavior of insect hosts. Insect Sci. 27: 1-13.

Bian G., Xu Y., Lu P., Xie Y. \& Xi Z. 2010. The Endosymbiotic Bacterium Wolbachia Induces Resistance to Dengue Virus in Aedes aegypti. PLoS Pathog. 6: 1-10.

Bing X.-L., Zhao D.-S., Sun J.-T., Zhang K.-J. \& Hong X.-Y. 2020. Genomic analysis of Wolbachia from Laodelphax striatellus (Delphacidae, Hemiptera) reveals insights into its "Jekyll and Hyde" mode of infection pattern. Genome Biol. Evol. 12: 3818-3831.

Bleidorn C. \& Gerth M. 2018. A critical re-evaluation of multilocus sequence typing (MLST) efforts in Wolbachia. FEMS Microbiol. Ecol. 94: fix163. 
Boman H.G. \& Hultmark D. 1987. Cell-Free Immunity in Insects. Annu. Rev.

Microbiol. 41: 103-126.

Bonneau M., Atyame C., Beji M., Justy F., Cohen-Gonsaud M., Sicard M. \& Weill M. 2018. Culex pipiens crossing type diversity is governed by an amplified and polymorphic operon of Wolbachia. Nat. Commun. 9: 1-10.

Bordenstein S. \& Rosengaus R.B. 2005. Discovery of a Novel Wolbachia Supergroup in Isoptera. Curr. Microbiol. 51: 393-398.

Bordenstein S.R., O’Hara F.P. \& Werren J.H. 2001. Wolbachia -induced incompatibility precedes other hybrid incompatibilities in Nasonia. Nature. 409: 707-710.

Bourtzis K. \& O’Neill S. 1998. “Wolbachia” Infections and Arthropod Reproduction. BioScience. 48: 287-293.

Bourtzis K., Pettigrew M.M. \& O’Neill S.L. 2000. Wolbachia neither induces nor suppresses transcripts encoding antimicrobial peptides. Insect Mol. Biol. 9: 635-639.

Braquart-Varnier C., Raimond M., Mappa G., Chevalier F.D., Le Clec'h W. \& Sicard M. 2015. The Hematopoietic Organ: A Cornerstone for Wolbachia Propagation Between and Within Hosts. Front. Microbiol. 6: 1424.

Breeuwer J.A. \& Werren J.H. 1993. Cytoplasmic incompatibility and bacterial density in Nasonia vitripennis. Genetics. 135: 565-574.

Breeuwer J.A.J. \& Jacobs G. 1996. Wolbachia: intracellular manipulators of mite reproduction. Exp. Appl. Acarol. 20: 421-434.

Bright M. \& Bulgheresi S. 2010. A complex journey: transmission of microbial symbionts. Nat. Rev. Microbiol. 8: 218-230.

Brown A.N. \& Lloyd V.K. 2015. Evidence for horizontal transfer of Wolbachia by a Drosophila mite. Exp. Appl. Acarol. 66: 301-311. 
Brownlie J.C., Cass B.N., Riegler M., Witsenburg J.J., Iturbe-Ormaetxe I., McGraw E.A. \& O’Neill S.L. 2009. Evidence for Metabolic Provisioning by a Common Invertebrate Endosymbiont, Wolbachia pipientis, during Periods of Nutritional Stress. PLOS Pathog. 5: e1000368.

Burke D.J., Hoke A.J. \& Koch J. 2020. The emergence of beech leaf disease in Ohio: Probing the plant microbiome in search of the cause. For. Pathol. 50: e12579.

Caragata E.P., Pais F.S., Baton L.A., Silva J.B.L., Sorgine M.H.F. \& Moreira L.A. 2017. The transcriptome of the mosquito Aedes fluviatilis (Diptera: Culicidae), and transcriptional changes associated with its native Wolbachia infection. BMC Genomics. 18: 6.

Caragata E.P., Rancès E., Hedges L.M., Gofton A.W., Johnson K.N., O’Neill S.L. \& McGraw E.A. 2013. Dietary Cholesterol Modulates Pathogen Blocking by Wolbachia. PLOS Pathog. 9: e1003459.

Chandler J.A., Lang J.M., Bhatnagar S., Eisen J.A. \& Kopp A. 2011. Bacterial Communities of Diverse Drosophila Species: Ecological Context of a HostMicrobe Model System. PLOS Genet. 7: e1002272.

Charlat S., Duplouy A., Hornett E.A., Dyson E.A., Davies N., Roderick G.K., Wedell N. \& Hurst G.D. 2009. The joint evolutionary histories of Wolbachia and mitochondria in Hypolimnas bolina. BMC Evol. Biol. 9: 64.

Charlat S., Hurst G.D.D. \& Merçot H. 2003. Evolutionary consequences of Wolbachia infections. Trends Genet. 19: 217-223.

Charlat S., Riegler M., Baures I., Poinsot D., Stauffer C. \& Merclot H. 2004. Incipient Evolution of Wolbachia Compatibility Types. Evolution. 58: 1901-1908.

Charleston M.A. \& Perkins S.L. 2006. Traversing the tangle: Algorithms and applications for cophylogenetic studies. J. Biomed. Inform. 39: 62-71.

Charleston M.A. \& Robertson D.L. 2002. Preferential Host Switching by Primate Lentiviruses Can Account for Phylogenetic Similarity with the Primate Phylogeny. Syst. Biol. 51: 528-535. 
Charlesworth J., Weinert L.A., Araujo J.E. \& Welch J.J. 2019. Wolbachia, Cardinium and climate: an analysis of global data. Biol. Lett. 15: $20190273-20190273$.

Cheng Q., Ruel T.D., Zhou W., Moloo S.K., Majiwa P., O’neill S.L. \& Aksoy S. 2000. Tissue distribution and prevalence of Wolbachia infections in tsetse flies, Glossina spp. Med. Vet. Entomol. 14: 44-50.

Chevalier F., Herbinière-Gaboreau J., Charif D., Mitta G., Gavory F., Wincker P., Grève P., Braquart-Varnier C. \& Bouchon D. 2012. Feminizing Wolbachia: a transcriptomics approach with insights on the immune response genes in Armadillidium vulgare. BMC Microbiol. 12: S1.

Chrostek E. \& Gerth M. 2019. Is Anopheles gambiae a Natural Host of Wolbachia?. mBio. 10: e00784-19.

Chrostek E., Pelz-Stelinski K., Hurst G.D.D. \& Hughes G.L. 2017. Horizontal Transmission of Intracellular Insect Symbionts via Plants. Front. Microbiol. 8: 2237.

Clancy D.J. \& Hoffmann A.A. 1997. Behavior of Wolbachia Endosymbionts from Drosophila simulans in Drosophila serrata, aNovel Host. Am. Nat. 149: 975988.

Clayton D.H., Bush S.E., Goates B.M. \& Johnson K.P. 2003. Host defense reinforces host-parasite cospeciation. Proc. Natl. Acad. Sci. 100: 15694-15699.

Combes C. 2001. Parasitism: The Ecology and Evolution of Intimate Interactions. University of Chicago Press, 743 pp.

Cook J.M. \& Butcher R.D.J. 1999. The transmission and effects of $<$ Emphasis Type="Italic" $>$ Wolbachia $</$ Emphasis $>$ bacteria in parasitoids. Res. Popul. Ecol. 41: 15-28.

Cooper B.S., Vanderpool D., Conner W.R., Matute D.R. \& Turelli M. 2019. Wolbachia Acquisition by Drosophila yakuba-Clade Hosts and Transfer of Incompatibility Loci Between Distantly Related Wolbachia. Genetics. 212: $1399-1419$. 
Corbin C., Heyworth E.R., Ferrari J. \& Hurst G.D.D. 2017. Heritable symbionts in a world of varying temperature. Heredity. 118: 10-20.

Cordaux R., Bouchon D. \& Grève P. 2011. The impact of endosymbionts on the evolution of host sex-determination mechanisms. Trends Genet. 27: 332-341.

Cordaux R., Michel-Salzat A. \& Bouchon D. 2001. Wolbachia infection in crustaceans: novel hosts and potential routes for horizontal transmission. J. Evol. Biol. 14: 237-243.

Cosmides M.L. \& Tooby J. 1981. Cytoplasmic inheritance and intragenomic conflict. J. Theor. Biol. 89: 83-129.

Darby A.C., Armstrong S.D., Bah G.S., Kaur G., Hughes M.A., Kay S.M., Koldkjær P., Rainbow L., Radford A.D., Blaxter M.L., Tanya V.N., Trees A.J., Cordaux R., Wastling J.M. \& Makepeace B.L. 2012. Analysis of gene expression from the Wolbachia genome of a filarial nematode supports both metabolic and defensive roles within the symbiosis. Genome Res. 22: 2467-2477.

Dedeine F., Ahrens M., Calcaterra L. \& Shoemaker D.D. 2005. Social parasitism in fire ants (Solenopsis spp.): a potential mechanism for interspecies transfer of Wolbachia. Mol. Ecol. 14: 1543-1548.

Detcharoen M., Arthofer W., Schlick-Steiner B.C. \& Steiner F.M. 2019. Wolbachia megadiversity: $99 \%$ of these microorganismic manipulators unknown. FEMS Microbiol. Ecol. 95: .

Dillon R.J. \& Dillon V.M. 2004. THE GUT BACTERIA OF INSECTS: Nonpathogenic Interactions. Annu. Rev. Entomol. 49: 71-92.

Dittmer J. \& Bouchon D. 2018. Feminizing Wolbachia influence microbiota composition in the terrestrial isopod Armadillidium vulgare. Sci. Rep. 8: 6998.

Dobson S.L., Bordenstein S.R. \& Rose R.I. 2016. Wolbachia mosquito control: Regulated. Science. 352: 526-527. 
Dobson S.L., Bourtzis K., Braig H.R., Jones B.F., Zhou W., Rousset F. \& O’Neill S.L. 1999. Wolbachia infections are distributed throughout insect somatic and germ line tissues. Insect Biochem. Mol. Biol. 29: 153-160.

Dobson S.L., Rattanadechakul W. \& Marsland E.J. 2004. Fitness advantage and cytoplasmic incompatibility in Wolbachia single- and superinfected Aedes albopictus. Heredity. 93: 135-142.

Douglas A.E. 2009. The microbial dimension in insect nutritional ecology. Funct. Ecol. 23: 38-47.

Dow J.A.T. 1987. Insect Midgut Function. pp. 187-328. In: Evans P.D. \& Wigglesworth V.B. (eds), Advances in Insect Physiology, Academic Press,

Duan X.-Z., Sun J.-T., Wang L.-T., Shu X.-H., Guo Y., Keiichiro M., Zhu Y.-X., Bing X.-L., Hoffmann A.A. \& Hong X.-Y. 2020. Recent infection by Wolbachia alters microbial communities in wild Laodelphax striatellus populations. Microbiome. 8: 104.

Dyer K.A. \& Jaenike J. 2004. Evolutionarily Stable Infection by a Male-Killing Endosymbiont in Drosophila innubila: Molecular Evidence From the Host and Parasite Genomes. Genetics. 168: 1443-1455.

Ekwudu O., Devine G.J., Aaskov J.G. \& Frentiu F.D. 2020. Wolbachia strain wAlbB blocks replication of flaviviruses and alphaviruses in mosquito cell culture. Parasit. Vectors. 13: 54.

Eleftherianos I., Atri J., Accetta J. \& Castillo J.C. 2013. Endosymbiotic bacteria in insects: guardians of the immune system?. Front. Physiol. 4: 46.

Ellegaard K.M., Klasson L., Näslund K., Bourtzis K. \& Andersson S.G.E. 2013. Comparative Genomics of Wolbachia and the Bacterial Species Concept. PLOS Genet. 9: e1003381.

Emerson K.J. \& Glaser R.L. 2017. Cytonuclear Epistasis Controls the Density of Symbiont Wolbachia pipientis in Nongonadal Tissues of Mosquito Culex quinquefasciatus. G3 Genes Genomes Genet. 7: 2627-2635. 
Engel P. \& Moran N.A. 2013. The gut microbiota of insects - diversity in structure and function. FEMS Microbiol. Rev. 37: 699-735.

Engelstädter J. \& Fortuna N.Z. 2019. The dynamics of preferential host switching: Host phylogeny as a key predictor of parasite distribution. Evolution. 73: $1330-1340$.

Engelstädter J. \& Hurst G.D.D. 2006. The dynamics of parasite incidence across host species. Evol. Ecol. 20: 603-616.

Engelstädter J. \& Hurst G.D.D. 2009. The Ecology and Evolution of Microbes that Manipulate Host Reproduction. Annu. Rev. Ecol. Evol. Syst. 40: 127-149.

Engelstädter J., Telschow A. \& Hammerstein P. 2004. Infection dynamics of different Wolbachia-types within one host population. J. Theor. Biol. 231: 345-355.

Enigl M. \& Schausberger P. 2007. Incidence of the endosymbionts Wolbachia, Cardinium and Spiroplasma in phytoseiid mites and associated prey. Exp. Appl. Acarol. 42: 75-85.

Enigl M., Zchori-Fein E. \& Schausberger P. 2005. Negative Evidence of Wolbachia in the Predaceous Mite Phytoseiulus persimilis. Exp. Appl. Acarol. 36: 249262.

Faria N.R., Suchard M.A., Rambaut A., Streicker D.G. \& Lemey P. 2013. Simultaneously reconstructing viral cross-species transmission history and identifying the underlying constraints. Philos. Trans. R. Soc. B Biol. Sci. 368: 20120196.

Fast E.M., Toomey M.E., Panaram K., Desjardins D., Kolaczyk E.D. \& Frydman H.M. 2011. Wolbachia Enhance Drosophila Stem Cell Proliferation and Target the Germline Stem Cell Niche. Science. 334: 990-992.

Fenn K. \& Blaxter M. 2004. Are filarial nematode Wolbachia obligate mutualist symbionts?. Trends Ecol. Evol. 19: 163-166.

Fenn K. \& Blaxter M. 2006. Wolbachia genomes: revealing the biology of parasitism and mutualism. Trends Parasitol. 22: 60-65. 
Fenton A., Johnson K.N., Brownlie J.C. \& Hurst G.D.D. 2011. Solving the Wolbachia Paradox: Modeling the Tripartite Interaction between Host, Wolbachia, and a Natural Enemy. Am. Nat. 178: 333-342.

Ferri E., Bain O., Barbuto M., Martin C., Lo N., Uni S., Landmann F., Baccei S.G., Guerrero R., Lima S. de S., Bandi C., Wanji S., Diagne M. \& Casiraghi M. 2011. New Insights into the Evolution of Wolbachia Infections in Filarial Nematodes Inferred from a Large Range of Screened Species. PLOS ONE. 6: e20843.

Fine P.E.M. 1978. On the dynamics of symbiote-dependent cytoplasmic incompatibility in culicine mosquitoes. J. Invertebr. Pathol. 31: 10-18.

Fleury F., Vavre F., Ris N., Fouillet P. \& Boulétreau M. 2000. Physiological cost induced by the maternally-transmitted endosymbiont Wolbachia in the Drosophila parasitoid Leptopilina heterotoma. Parasitology. 121: 493-500.

Floate K.D., Kyei-Poku G.K. \& Coghlin P.C. 2006. Overview and relevance of Wolbachia bacteria in biocontrol research. Biocontrol Sci. Technol. 16: 767788.

Frank S.A. 1997. Recognition and polymorphism in host-parasite genetics. pp. 13-23. In: Hamilton W.D. \& Howard J.C. (eds), Infection, Polymorphism and Evolution, Springer Netherlands, Dordrecht.

Frank S.A. 1998. Dynamics of Cytoplasmic Incompatability with MultipleWolbachiaInfections. J. Theor. Biol. 192: 213-218.

Fromont C., Adair K.L. \& Douglas A.E. 2019. Correlation and causation between the microbiome, Wolbachia and host functional traits in natural populations of drosophilid flies. Mol. Ecol. 28: 1826-1841.

Frost C.L., Fernandez-Marin H., Smith J.E. \& Hughes W.O.H. 2010. Multiple gains and losses of Wolbachia symbionts across a tribe of fungus-growing ants. Mol. Ecol. 19: 4077-4085. 
Frost C.L., Pollock S.W., Smith J.E. \& Hughes W.O.H. 2014. Wolbachia in the Flesh: Symbiont Intensities in Germ-Line and Somatic Tissues Challenge the Conventional View of Wolbachia Transmission Routes. PLOS ONE. 9: e95122.

Frydman H.M., Li J.M., Robson D.N. \& Wieschaus E. 2006. Somatic stem cell niche tropism in Wolbachia. Nature. 441: 509-512.

Funkhouser-Jones L.J., van Opstal E.J., Sharma A. \& Bordenstein S.R. 2018. The Maternal Effect Gene Wds Controls Wolbachia Titer in Nasonia. Curr. Biol. 28: 1692-1702.e6.

Gerth M. 2016. Classification of Wolbachia (Alphaproteobacteria, Rickettsiales): No evidence for a distinct supergroup in cave spiders. Infect. Genet. Evol. J. Mol. Epidemiol. Evol. Genet. Infect. Dis. 43: 378-380.

Gerth M. \& Bleidorn C. 2017. Comparative genomics provides a timeframe for Wolbachia evolution and exposes a recent biotin synthesis operon transfer. Nat. Microbiol. 2: 16241.

Gerth M., Röthe J. \& Bleidorn C. 2013. Tracing horizontal Wolbachia movements among bees (Anthophila): a combined approach using multilocus sequence typing data and host phylogeny. Mol. Ecol. 22: 6149-6162.

Gilbert G.S. \& Webb C.O. 2007. Phylogenetic signal in plant pathogen-host range. Proc. Natl. Acad. Sci. 104: 4979-4983.

Glowska E., Dragun-Damian A., Dabert M. \& Gerth M. 2015. New Wolbachia supergroups detected in quill mites (Acari: Syringophilidae). Infect. Genet. Evol. 30: 140-146.

Godfray H.C.J. 1994. Parasitoids: Behavioral and Evolutionary Ecology. Princeton University Press, 483 pp.

Gonella E., Pajoro M., Marzorati M., Crotti E., Mandrioli M., Pontini M., Bulgari D., Negri I., Sacchi L., Chouaia B., Daffonchio D. \& Alma A. 2015. Plant- 
mediated interspecific horizontal transmission of an intracellular symbiont in insects. Sci. Rep. 5: 15811.

Guidolin A.S. \& Cônsoli F.L. 2017. Symbiont Diversity of Aphis (Toxoptera) citricidus (Hemiptera: Aphididae) as Influenced by Host Plants. Microb. Ecol. 73: $201-210$.

Guo Y., Gong J.-T., Mo P.-W., Huang H.-J. \& Hong X.-Y. 2019. Wolbachia localization during Laodelphax striatellus embryogenesis. J. Insect Physiol. 116: $125-133$.

Guo Y., Hoffmann A.A., Xu X.-Q., Mo P.-W., Huang H.-J., Gong J.-T., Ju J.-F. \& Hong X.-Y. 2018. Vertical Transmission of Wolbachia Is Associated With Host Vitellogenin in Laodelphax striatellus. Front. Microbiol. 9: .

Guz N., Kocak E., Akpinar A., Gurkan M.O. \& Kilincer A.N. 2012. Wolbachia infection in Trissolcus species (Hymenoptera: Scelionidae). Eur. J. Entomol. 109: 169-174.

Hafner M.S. \& Nadler S.A. 1990. Cospeciation in Host-Parasite Assemblages: Comparative Analysis of Rates of Evolution and Timing of Cospeciation Events. Syst. Biol. 39: 192-204.

Haine E.R. \& Cook J.M. 2005. Convergent incidences of Wolbachia infection in fig wasp communities from two continents. Proc. R. Soc. B Biol. Sci. 272: $421-$ 429.

Haine E.R., Pickup N.J. \& Cook J.M. 2005. Horizontal transmission of Wolbachia in a Drosophila community. Ecol. Entomol. 30: 464-472.

Hale L.R. \& Hoffmann A.A. 1990. Mitochondrial DNA Polymorphism and Cytoplasmic Incompatibility in Natural Populations of Drosophila simulans. Evolution. 44: 1383-1386.

Hancock P.A., White V.L., Ritchie S.A., Hoffmann A.A. \& Godfray H.C.J. 2016. Predicting Wolbachia invasion dynamics in Aedes aegypti populations using models of density-dependent demographic traits. BMC Biol. 14: 96. 
Hassell M.P. 1978. The Dynamics of Arthropod Predator-prey Systems. Princeton University Press, 248 pp.

Heath B.D., Butcher R.D.J., Whitfield W.G.F. \& Hubbard S.F. 1999. Horizontal transfer of Wolbachia between phylogenetically distant insect species by a naturally occurring mechanism. Curr. Biol. 9: 313-316.

Hedges L.M., Brownlie J.C., O’Neill S.L. \& Johnson K.N. 2008. Wolbachia and Virus Protection in Insects. Science. 322: 702-702.

Henry L.M., Peccoud J., Simon J.-C., Hadfield J.D., Maiden M.J.C., Ferrari J. \& Godfray H.C.J. 2013. Horizontally Transmitted Symbionts and Host Colonization of Ecological Niches. Curr. Biol. 23: 1713-1717.

Herbert R.I. \& McGraw E.A. 2018. The nature of the immune response in novel $<$ Emphasis Type $=$ "Italic" $>$ Wolbachia $</$ Emphasis $>$-host associations. Symbiosis. 74: 225-236.

Hertig M. 1936. The Rickettsia, Wolbachia pipientis and Associated Inclusions of the Mosquito, Culex pipiens. Parasitology. 28: 453-486.

Hilgenboecker K., Hammerstein P., Schlattmann P., Telschow A. \& Werren J.H. 2008. How many species are infected with Wolbachia? - a statistical analysis of current data. FEMS Microbiol. Lett. 281: 215-220.

Hoffmann A.A., Montgomery B.L., Popovici J., Iturbe-Ormaetxe I., Johnson P.H., Muzzi F., Greenfield M., Durkan M., Leong Y.S., Dong Y., Cook H., Axford J., Callahan A.G., Kenny N., Omodei C., McGraw E.A., Ryan P.A., Ritchie S.A., Turelli M. \& O’Neill S.L. 2011. Successful establishment of Wolbachia in Aedes populations to suppress dengue transmission. Nature. 476: 454-457.

Hoffmann A.A., Ross P.A. \& Rašić G. 2015. Wolbachia strains for disease control: ecological and evolutionary considerations. Evol. Appl. 8: 751-768.

Hoffmann A.A., Turelli M. \& Harshman L.G. 1990. Factors affecting the distribution of cytoplasmic incompatibility in Drosophila simulans. Genetics. 126: 933948. 
Hornett E.A., Duplouy A.M.R., Davies N., Roderick G.K., Wedell N., Hurst G.D.D. \& Charlat S. 2008. You Can't Keep a Good Parasite down: Evolution of a Male-Killer Suppressor Uncovers Cytoplasmic Incompatibility. Evolution. 62: $1258-1263$.

Hornett E.A., Engelstädter J. \& Hurst G.D.D. 2010. Hidden cytoplasmic incompatibility alters the dynamics of male-killer/host interactions. J. Evol. Biol. 23: 479-487.

Hosokawa T., Kikuchi Y., Nikoh N., Shimada M. \& Fukatsu T. 2006. Strict HostSymbiont Cospeciation and Reductive Genome Evolution in Insect Gut Bacteria. PLOS Biol. 4: e337.

Hosokawa T., Koga R., Kikuchi Y., Meng X.-Y. \& Fukatsu T. 2010. Wolbachia as a bacteriocyte-associated nutritional mutualist. Proc. Natl. Acad. Sci. 107: 769774.

Hou H.-Q., Zhao G.-Z., Su C.-Y. \& Zhu D.-H. 2020. Wolbachia prevalence patterns: horizontal transmission, recombination, and multiple infections in chestnut gall wasp-parasitoid communities. Entomol. Exp. Appl. 168: .

Hughes G.L., Dodson B.L., Johnson R.M., Murdock C.C., Tsujimoto H., Suzuki Y., Patt A.A., Cui L., Nossa C.W., Barry R.M., Sakamoto J.M., Hornett E.A. \& Rasgon J.L. 2014. Native microbiome impedes vertical transmission of Wolbachia in Anopheles mosquitoes. Proc. Natl. Acad. Sci. 111: 1249812503.

Hughes G.L. \& Rasgon J.L. 2014. Transinfection: a method to investigate Wolbachia-host interactions and control arthropod-borne disease. Insect Mol. Biol. 23: 141-151.

Huigens M.E., Almeida R.P. de, Boons P. a. H., Luck R.F. \& Stouthamer R. 2004a. Natural interspecific and intraspecific horizontal transfer of parthenogenesisinducing Wolbachia in Trichogramma wasps. Proc. R. Soc. Lond. B Biol. Sci. 271: 509-515. 
Huigens M.E., Hohmann C.L., Luck R.F., Gort G. \& Stouthamer R. 2004b. Reduced competitive ability due to Wolbachia infection in the parasitoid wasp Trichogramma kaykai. Entomol. Exp. Appl. 110: 115-123.

Huigens M.E., Luck R.F., Klaassen R.H.G., Maas M., Timmermans M. \& Stouthamer R. 2000. Infectious parthenogenesis. Nature. 405: 178-179.

Hunter M.S., Perlman S.J. \& Kelly S.E. 2003. A bacterial symbiont in the Bacteroidetes induces cytoplasmic incompatibility in the parasitoid wasp Encarsia pergandiella. Proc. R. Soc. Lond. B Biol. Sci. 270: 2185-2190.

Hurst G.D.D., Hurst L.D. \& Majerus M.E.N. 1992. Selfish genes move sideways. Nature. 356: 659-660.

Hurst G.D.D., Johnson A.P., Schulenburg J.H.G. v d \& Fuyama Y. 2000. MaleKilling Wolbachia in Drosophila: A Temperature-Sensitive Trait With a Threshold Bacterial Density. Genetics. 156: 699-709.

Hurst G.D.D. \& Majerus M.E.N. 1993. Why do maternally inherited microorganisms kill males? Heredity. 71: 81-95.

Hurst L.D. \& McVean G.T. 1996. Clade selection, reversible evolution and the persistence of selfish elements: the evolutionary dynamics of cytoplasmic incompatibility. Proc. R. Soc. Lond. B Biol. Sci. 263: 97-104.

Hurst T.P., Pittman G., O’Neill S.L., Ryan P.A., Le Nguyen H. \& Kay B.H. 2012. Impacts of Wolbachia Infection on Predator Prey Relationships: Evaluating Survival and Horizontal Transfer Between wMelPop Infected Aedes aegypti and Its Predators. J. Med. Entomol. 49: 624-630.

Ilinsky Y.\& Kosterin O.E. 2017. Molecular diversity of Wolbachia in Lepidoptera: Prevalent allelic content and high recombination of MLST genes. Mol. Phylogenet. Evol. 109: 164-179.

Isberg R.R., O’Connor T.J. \& Heidtman M. 2009. The Legionella pneumophila replication vacuole: making a cosy niche inside host cells. Nat. Rev. Microbiol. 7: 13-24. 
Ishmael N., Hotopp J.C.D., Ioannidis P., Biber S., Sakamoto J., Siozios S., Nene V., Werren J., Bourtzis K., Bordenstein S.R. \& Tettelin H. 2009. Extensive genomic diversity of closely related Wolbachia strains. Microbiology. 155: $2211-2222$.

Iturbe-Ormaetxe I., Walker T. \& Neill S.L.O. 2011. Wolbachia and the biological control of mosquito-borne disease. EMBO Rep. 12: 508-518.

Jansen V.A.A., Turelli M. \& Godfray H.C.J. 2008. Stochastic spread of Wolbachia. Proc. R. Soc. B Biol. Sci. 275: 2769-2776.

Jiggins F.M. 2002. The Rate of Recombination in Wolbachia Bacteria. Mol. Biol. Evol. 19: 1640-1643.

Jiggins F.M. 2003. Male-Killing Wolbachia and Mitochondrial DNA: Selective Sweeps, Hybrid Introgression and Parasite Population Dynamics. Genetics. 164: $5-12$.

Jiggins F.M., Bentley J.K., Majerus N.M.E. \& Hurst D.G. 2002. Recent changes in phenotype and patterns of host specialization in Wolbachia bacteria. Mol. Ecol. 11: 1275-1283.

Jiggins Francis M., Schulenburg J. Hinrich G. von der, Hurst Gregory D. D. \& Majerus Michael E. N. 2001. Recombination confounds interpretations of Wolbachia evolution. Proc. R. Soc. Lond. B Biol. Sci. 268: 1423-1427.

Johannesen J. 2017. Tracing the history and ecological context of Wolbachia double infection in a specialist host (Urophora cardui) — parasitoid (Eurytoma serratulae) system. Ecol. Evol. 7: 986-996.

Johanowicz D.L. \& Hoy M.A. 1996. Wolbachia in a Predator-Prey System: 16S Ribosomal Dna Analysis of Two Phytoseiids (Acari: Phytoseiidae) and Their Prey (Acari: Tetranychidae). Ann. Entomol. Soc. Am. 89: 435-441.

Joubert D.A., Walker T., Carrington L.B., Bruyne J.T.D., Kien D.H.T., Hoang N.L.T., Chau N.V.V., Iturbe-Ormaetxe I., Simmons C.P. \& O’Neill S.L. 2016. Establishment of a Wolbachia Superinfection in Aedes aegypti Mosquitoes as 
a Potential Approach for Future Resistance Management. PLOS Pathog. 12: e1005434.

Ju J.-F., Bing X.-L., Zhao D.-S., Guo Y., Xi Z., Hoffmann A.A., Zhang K.-J., Huang H.-J., Gong J.-T., Zhang X. \& Hong X.-Y. 2020. Wolbachia supplement biotin and riboflavin to enhance reproduction in planthoppers. ISME J. 14: 676-687.

Kageyama D., Narita S., Imamura T. \& Miyanoshita A. 2010. Detection and identification of Wolbachia endosymbionts from laboratory stocks of storedproduct insect pests and their parasitoids. J. Stored Prod. Res. 46: 13-19.

Kambris Z., Cook P.E., Phuc H.K. \& Sinkins S.P. 2009. Immune Activation by LifeShortening Wolbachia and Reduced Filarial Competence in Mosquitoes. Science. 326: 134-136.

Keeling M.J., Jiggins F.M. \& Read J.M. 2003. The invasion and coexistence of competing Wolbachia strains. Heredity. 91: 382-388.

Keeling M.J. \& Rohani P. 2011. Modeling Infectious Diseases in Humans and Animals. Princeton University Press, 385 pp.

Kennedy S.R., Tsau S., Gillespie R. \& Krehenwinkel H. 2020. Are you what you eat? A highly transient and prey-influenced gut microbiome in the grey house spider Badumna longinqua. Mol. Ecol. 2020;00: 1-15.

Kent B.N. \& Bordenstein S.R. 2010. Phage WO of Wolbachia: lambda of the endosymbiont world. Trends Microbiol. 18: 173-181.

Kikuchi Y. \& Fukatsu T. 2003. Diversity of Wolbachia Endosymbionts in Heteropteran Bugs. Appl Env. Microbiol. 69: 6082-6090.

Kittayapong P., Jamnongluk W., Thipaksorn A., Milne J.R. \& Sindhusake C. 2003. Wolbachia infection complexity among insects in the tropical rice-field community. Mol. Ecol. 12: 1049-1060.

Klasson L., Westberg J., Sapountzis P., Näslund K., Lutnaes Y., Darby A.C., Veneti Z., Chen L., Braig H.R., Garrett R., Bourtzis K. \& Andersson S.G.E. 2009. 
The mosaic genome structure of the Wolbachia wRi strain infecting Drosophila simulans. Proc. Natl. Acad. Sci. 106: 5725-5730.

Klopfstein S., van Der Schyff G., Tierney S. \& Austin A.D. 2018. Wolbachia infections in Australian ichneumonid parasitoid wasps (Hymenoptera: Ichneumonidae): evidence for adherence to the global equilibrium hypothesis. Biol. J. Linn. Soc. 123: 518-534.

Koehncke A., Telschow A., Werren J.H. \& Hammerstein P. 2009. Life and Death of an Influential Passenger: Wolbachia and the Evolution of CI-Modifiers by Their Hosts. PLOS ONE. 4: e4425.

Koga R., Meng X.-Y., Tsuchida T. \& Fukatsu T. 2012. Cellular mechanism for selective vertical transmission of an obligate insect symbiont at the bacteriocyte-embryo interface. Proc. Natl. Acad. Sci. 109: E1230-E1237.

Kondo N., Ijichi N., Shimada M. \& Fukatsu T. 2002. Prevailing triple infection with Wolbachia in Callosobruchus chinensis (Coleoptera: Bruchidae). Mol. Ecol. 11: $167-180$.

Kriesner P., Conner W.R., Weeks A.R., Turelli M. \& Hoffmann A.A. 2016. Persistence of a Wolbachia infection frequency cline in Drosophila melanogaster and the possible role of reproductive dormancy. Evolution. 70: 979-997.

Kriesner P., Hoffmann A.A., Lee S.F., Turelli M. \& Weeks A.R. 2013. Rapid Sequential Spread of Two Wolbachia Variants in Drosophila simulans. PLOS Pathog. 9: e1003607.

Lachowska D., Kajtoch Ł. \& Knutelski S. 2010. Occurrence of Wolbachia in central European weevils: correlations with host systematics, ecology, and biology. Entomol. Exp. Appl. 135: 105-118.

Landmann F. 2019. The Wolbachia Endosymbionts. pp. 139-214. Bacteria and Interacellularity, Wiley, ASM PRESS, Washington, DC. 
Lavine M.D. \& Strand M.R. 2002. Insect hemocytes and their role in immunity. Insect Biochem. Mol. Biol. 32: 1295-1309.

Le Clec'h W., Chevalier F.D., Genty L., Bertaux J., Bouchon D. \& Sicard M. 2013. Cannibalism and predation as paths for horizontal passage of Wolbachia between terrestrial isopods. PloS One. 8: e60232.

Le Clec'h W., Dittmer J., Raimond M., Bouchon D. \& Sicard M. 2017. Phenotypic shift in Wolbachia virulence towards its native host across serial horizontal passages. Proc. R. Soc. B Biol. Sci. 284: 20171076.

Le Clec'h W.L., Braquart-Varnier C., Raimond M., Ferdy J.-B., Bouchon D. \& Sicard M. 2012. High Virulence of Wolbachia after Host Switching: When Autophagy Hurts. PLOS Pathog. 8: e1002844.

Leclercq S., Giraud I. \& Cordaux R. 2011. Remarkable Abundance and Evolution of Mobile Group II Introns in Wolbachia Bacterial Endosymbionts. Mol. Biol. Evol. 28: 685-697.

Lefoulon E., Clark T., Borveto F., Perriat-Sanguinet M., Moulia C., Slatko B.E. \& Gavotte L. 2020. Pseudoscorpion Wolbachia symbionts: diversity and evidence for a new supergroup S. BMC Microbiol. 20: 188.

Lemoine M., Engl T. \& Kaltenpoth M. 2020. Microbial symbionts expanding or constraining abiotic niche space in insects. Curr. Opin. Insect Sci. 39: 14-20.

Li C., He M., Yun Y. \& Peng Y. 2020. Co-infection with Wolbachia and Cardinium may promote the synthesis of fat and free amino acids in a small spider, Hylyphantes graminicola. J. Invertebr. Pathol. 169: 107307.

Li D. \& Wan H. 2019. The Threshold Infection Level for Wolbachia Invasion in a Two-Sex Mosquito Population Model. Bull. Math. Biol. 266: 4377-4393.

Li J., Wang N., Liu Y. \& Qiu S. 2018. Proteomics of Nasonia vitripennis and the effects of native Wolbachia infection on N. vitripennis. PeerJ. 6: e4905. 
Li S.-J., Ahmed M.Z., Lv N., Shi P.-Q., Wang X.-M., Huang J.-L. \& Qiu B.-L. 2017a. Plantmediated horizontal transmission of Wolbachia between whiteflies. ISME J. 11: 1019-1028.

Li Y.-H., Ahmed M.Z., Li S.-J., Lv N., Shi P.-Q., Chen X.-S. \& Qiu B.-L. 2017b. Plant-mediated horizontal transmission of Rickettsia endosymbiont between different whitefly species. FEMS Microbiol. Ecol. 93: 138.

Licht H.H.D.F. 2018. Does pathogen plasticity facilitate host shifts?. PLOS Pathog. 14: e1006961.

Lindsey A.R.I. 2020. Sensing, Signaling, and Secretion: A Review and Analysis of Systems for Regulating Host Interaction in Wolbachia. Genes. 11: 813.

Lindsey A.R.I., Bordenstein S.R., Newton I.L.G. \& Rasgon J.L. 2016. Wolbachia pipientis should not be split into multiple species: A response to RamírezPuebla et al., "Species in Wolbachia? Proposal for the designation of 'Candidatus Wolbachia bourtzisii', 'Candidatus Wolbachia onchocercicola', 'Candidatus Wolbachia blaxteri', 'Candidatus Wolbachia brugii', 'Candidatus Wolbachia taylori', 'Candidatus Wolbachia collembolicola' and 'Candidatus Wolbachia multihospitum' for the different species within Wolbachia supergroups.” Syst. Appl. Microbiol. 39: 220-222.

Liu X.-D. \& Guo H.-F. 2019. Importance of endosymbionts Wolbachia and Rickettsia in insect resistance development. Curr. Opin. Insect Sci. 33: 84-90.

Lo N., Casiraghi M., Salati E., Bazzocchi C. \& Bandi C. 2002. How Many Wolbachia Supergroups Exist?. Mol. Biol. Evol. 19: 341-346.

Longdon B., Hadfield J.D., Webster C.L., Obbard D.J. \& Jiggins F.M. 2011. Host Phylogeny Determines Viral Persistence and Replication in Novel Hosts. PLOS Pathog. 7: e1002260.

López-Madrigal S. \& Duarte E.H. 2019. Titer regulation in arthropod-Wolbachia symbioses. FEMS Microbiol. Lett. 366: fn232. 
Loreto E.L.S. \& Wallau G.L. 2016. Risks of Wolbachia mosquito control. Science. 351: 1273-1273.

Lv N., Peng J., Chen X.-Y., Guo C.-F., Sang W., Wang X.-M., Ahmed M.Z., Xu Y.Y. \& Qiu B.-L. 2020. Antagonistic interaction between male-killing and cytoplasmic incompatibility induced by Cardinium and Wolbachia in the whitefly, Bemisia tabaci. Insect Sci. .

Mallet J. 2005. Hybridization as an invasion of the genome. Trends Ecol. Evol. 20: $229-237$.

Martínez-Rodríguez P. \& Bella J.L. 2018. Chorthippus parallelus and Wolbachia: Overlapping Orthopteroid and Bacterial Hybrid Zones. Front. Genet. 9: 604.

McFrederick Q.S. \& Rehan S.M. 2016. Characterization of pollen and bacterial community composition in brood provisions of a small carpenter bee. Mol. Ecol. 25: 2302-2311.

McLean A.H.C., Parker B.J., Hrček J., Kavanagh J.C., Wellham P.A.D. \& Godfray H.C.J. 2018. Consequences of symbiont co-infections for insect host phenotypes. J. Anim. Ecol. 87: 478-488.

Meer M.M.M.V. \& Stouthamer R. 1999. Cross-order transfer of Wolbachia from Muscidifurax uniraptor (Hymenoptera: Pteromalidae) to Drosophila simulans (Diptera: Drosophilidae). Heredity. 82: 163-169.

Meer M.M.M.V., Witteveldt J. \& Stouthamer R. 1999. Phylogeny of the arthropod endosymbiont Wolbachia based on the wsp gene. Insect Mol. Biol. 8: 399408.

Mertens K. \& Samuel J.E. 2012. Defense Mechanisms Against Oxidative Stress in Coxiella burnetii: Adaptation to a Unique Intracellular Niche. pp. 39-63. In: Toman R., Heinzen R.A., Samuel J.E., \& Mege J.-L. (eds), Coxiella burnetii: Recent Advances and New Perspectives in Research of the Q Fever Bacterium, Springer Netherlands, Dordrecht. 
Mills N. 2009. Chapter 190 - Parasitoids. pp. 748-751. In: Resh V.H. \& Cardé R.T. (eds), Encyclopedia of Insects (Second Edition), Academic Press, San Diego.

Min K.-T. \& Benzer S. 1997. Wolbachia, normally a symbiont of Drosophila, can be virulent, causing degeneration and early death. Proc. Natl. Acad. Sci. 94: 10792-10796.

Miraldo A. \& Duplouy A. 2019. High Wolbachia Strain Diversity in a Clade of Dung Beetles Endemic to Madagascar. Front. Ecol. Evol. 7: 157.

Miyata M.N., Nomura M. \& Kageyama D. 2020. Wolbachia have made it twice: Hybrid introgression between two sister species of Eurema butterflies. Ecol. Evol. 10: .

Morand S., Krasnov B.R. \& Littlewood D.T.J. 2015. Parasite Diversity and Diversification. Cambridge University Press, 503 pp.

Moriyama M., Nikoh N., Hosokawa T. \& Fukatsu T. 2015. Riboflavin Provisioning Underlies Wolbachia's Fitness Contribution to Its Insect Host. mBio. 6: e01732-01715.

Morrow J.L., Frommer M., Shearman D.C.A. \& Riegler M. 2014. Tropical tephritid fruit fly community with high incidence of shared Wolbachia strains as platform for horizontal transmission of endosymbionts. Environ. Microbiol. 16: $3622-3637$.

Mouton L., Henri H., Bouletreau M. \& Vavre F. 2006. Effect of temperature on Wolbachia density and impact on cytoplasmic incompatibility. Parasitology. 132: $49-56$.

Newton I.L.G., Savytskyy O. \& Sheehan K.B. 2015. Wolbachia Utilize Host Actin for Efficient Maternal Transmission in Drosophila melanogaster. PLOS Pathog. 11: e1004798.

Nikoh N., Hosokawa T., Moriyama M., Oshima K., Hattori M. \& Fukatsu T. 2014. Evolutionary origin of insect-Wolbachia nutritional mutualism. Proc. Natl. Acad. Sci. 111: 10257-10262. 
Nikolouli K., Colinet H., Renault D., Enriquez T., Mouton L., Gibert P., Sassu F., Cáceres C., Stauffer C., Pereira R. \& Bourtzis K. 2018. Sterile insect technique and $<$ Emphasis Type $=$ "Italic" $>$ Wolbachia $</$ Emphasis $>$ symbiosis as potential tools for the control of the invasive species $<$ Emphasis Type="Italic" $>$ Drosophila suzukii $</$ Emphasis $>$. J. Pest Sci. 91: 489-503.

Noda H., Miyoshi T., Zhang Q., Watanabe K., Deng K. \& Hoshizaki S. 2001. Wolbachia infection shared among planthoppers (Homoptera: Delphacidae) and their endoparasite (Strepsiptera: Elenchidae): a probable case of interspecies transmission. Mol. Ecol. 10: 2101-2106.

O’Neill S.L. 2018. The Use of Wolbachia by the World Mosquito Program to Interrupt Transmission of Aedes aegypti Transmitted Viruses. pp. 355-360. In: Hilgenfeld R. \& Vasudevan S.G. (eds), Dengue and Zika: Control and Antiviral Treatment Strategies, Springer Singapore, Singapore.

O’Neill S.L., Giordano R., Colbert A.M., Karr T.L. \& Robertson H.M. 1992. 16S rRNA phylogenetic analysis of the bacterial endosymbionts associated with cytoplasmic incompatibility in insects. Proc. Natl. Acad. Sci. 89: 2699-2702.

O’Neill S.L., Hoffmann A. \& Werren J. 1997. Influential Passengers: Inherited Microorganisms and Arthropod Reproduction. Oxford University Press,

Osborne S.E., Iturbe-Ormaetxe I., Brownlie J.C., O’Neill S.L. \& Johnson K.N. 2012. Antiviral protection and the importance of Wolbachia density and tissue tropism in Drosophila. Appl Env. Microbiol. AEM.01727-12.

Otten C., Brilli M., Vollmer W., Viollier P.H. \& Salje J. 2018. Peptidoglycan in obligate intracellular bacteria. Mol. Microbiol. 107: 142-163.

Paine R.T. 1980. Food Webs: Linkage, Interaction Strength and Community Infrastructure. J. Anim. Ecol. 49: 667-685.

Pan X., Zhou G., Wu J., Bian G., Lu P., Raikhel A.S. \& Xi Z. 2012. Wolbachia induces reactive oxygen species (ROS)-dependent activation of the Toll pathway to control dengue virus in the mosquito Aedes aegypti. Proc. Natl. Acad. Sci. 109: E23-E31. 
Peccoud J., Loiseau V., Cordaux R. \& Gilbert C. 2017. Massive horizontal transfer of transposable elements in insects. Proc. Natl. Acad. Sci. 114: 4721-4726.

Perez Ruiz M., MARTÍNEZ-RODRÍGUEZ P., HERRANZ J. \& L. BELLA J. 2015. A survey of Wolbachia, Spiroplasma and other bacteria in parthenogenetic and non-parthenogenetic phasmid (Phasmatodea) species - ProQuest. Eur J Entomol. 112: 409-418.

Perlman S.J. \& Jaenike J. 2003. Infection Success in Novel Hosts: An Experimental and Phylogenetic Study of Drosophila-Parasitic Nematodes. Evolution. 57: $544-557$.

Perlmutter J.I. \& Bordenstein S.R. 2020. Microorganisms in the reproductive tissues of arthropods. Nat. Rev. Microbiol. 18: 97-111.

Perrot-Minnot M.-J., Guo L.R. \& Werren J.H. 1996. Single and Double Infections with Wolbachia in the Parasitic Wasp Nasonia vitripennis Effects on Compatibility. Genetics. 143: 961-972.

Pietri J.E., DeBruhl H. \& Sullivan W. 2016. The rich somatic life of Wolbachia. MicrobiologyOpen. 5: 923-936.

Poinsot D., Bourtzis K., Markakis G., Savakis C. \& Merçot H. 1998. Wolbachia Transfer from Drosophila melanogaster into D. simulans: Host Effect and Cytoplasmic Incompatibility Relationships. Genetics. 150: 227-237.

Ramírez-Puebla S.T., Servín-Garcidueñas L.E., Ormeño-Orrillo E., Vera-Ponce de León A., Rosenblueth M., Delaye L., Martínez J. \& Martínez-Romero E. 2015. Species in Wolbachia? Proposal for the designation of 'Candidatus Wolbachia bourtzisii', 'Candidatus Wolbachia onchocercicola', 'Candidatus Wolbachia blaxteri', 'Candidatus Wolbachia brugii', 'Candidatus Wolbachia taylori', 'Candidatus Wolbachia collembolicola' and 'Candidatus Wolbachia multihospitum' for the different species within Wolbachia supergroups. Syst. Appl. Microbiol. 38: 390-399. 
Rancès E., Ye Y.H., Woolfit M., McGraw E.A. \& O’Neill S.L. 2012. The Relative Importance of Innate Immune Priming in Wolbachia-Mediated Dengue Interference. PLOS Pathog. 8: e1002548.

Rasgon J.L., Gamston C.E. \& Ren X. 2006. Survival of Wolbachia pipientis in CellFree Medium. Appl. Environ. Microbiol. 72: 6934-6937.

Rasgon J.L. \& Scott T.W. 2004. Impact of population age structure on Wolbachia transgene driver efficacy: ecologically complex factors and release of genetically modified mosquitoes. Insect Biochem. Mol. Biol. 34: 707-713.

Raychoudhury R., Baldo L., Oliveira D.C. \& Werren J.H. 2009. Modes of acquisition of Wolbachia: horizontal transfer, hybrid introgression, and codivergence in the Nasonia species complex. Evolution. 63: 165-183.

Read A.F. \& Taylor L.H. 2001. The Ecology of Genetically Diverse Infections. Science. 292: 1099-1102.

Reiss D., Mialdea G., Miele V., Vienne D.M. de, Peccoud J., Gilbert C., Duret L. \& Charlat S. 2019. Global survey of mobile DNA horizontal transfer in arthropods reveals Lepidoptera as a prime hotspot. PLOS Genet. 15: e1007965.

Reveillaud J., Bordenstein S.R., Cruaud C., Shaiber A., Esen Ö.C., Weill M., Makoundou P., Lolans K., Watson A.R., Rakotoarivony I., Bordenstein S.R. \& Eren A.M. 2019. The Wolbachia mobilome in Culex pipiens includes a putative plasmid. Nat. Commun. 10: 1051.

Reynolds K.T., Thomson L.J. \& Hoffmann A.A. 2003. The effects of host age, host nuclear background and temperature on phenotypic effects of the virulent Wolbachia strain popcorn in Drosophila melanogaster. Genetics. 164: 10271034.

Reynolds L.A., Hornett E.A., Jiggins C.D. \& Hurst G.D.D. 2019. Suppression of Wolbachia-mediated male-killing in the butterfly Hypolimnas bolina involves a single genomic region. PeerJ. 7: e7677. 
Richardson M.F., Weinert L.A., Welch J.J., Linheiro R.S., Magwire M.M., Jiggins F.M. \& Bergman C.M. 2012. Population Genomics of the Wolbachia Endosymbiont in Drosophila melanogaster. PLOS Genet. 8: e1003129.

Riegler M., Charlat S., Stauffer C. \& Merçot H. 2004. Wolbachia Transfer from Rhagoletis cerasi to Drosophila simulans: Investigating the Outcomes of HostSymbiont Coevolution. Appl Env. Microbiol. 70: 273-279.

Rigaud T. \& Juchault P. 1992. Genetic control of the vertical transmission of a cytoplasmic sex factor in Armadillidium vulgare Latr. (Crustacea, Oniscidea). Heredity. 68: 47-52.

Rigaud T. \& Juchault P. 1995. Success and failure of horizontal transfers of feminizing Wolbachia endosymbionts in woodlice. J. Evol. Biol. 8: 249-255.

Rigaud T., Pennings P.S. \& Juchault P. 2001. Wolbachia Bacteria Effects after Experimental Interspecific Transfers in Terrestrial Isopods. J. Invertebr. Pathol. 77: 251-257.

Ritchie S.A., van den Hurk A.F., Smout M.J., Staunton K.M. \& Hoffmann A.A. 2018. Mission Accomplished? We Need a Guide to the 'Post Release' World of Wolbachia for Aedes-borne Disease Control. Trends Parasitol. 34: 217-226.

Ritchie S.A., Townsend M., Paton C.J., Callahan A.G. \& Hoffmann A.A. 2015. Application of wMelPop Wolbachia Strain to Crash Local Populations of Aedes aegypti. PLoS Negl. Trop. Dis. 9: e0003930.

Rohrscheib C.E., Bondy E., Josh P., Riegler M., Eyles D., Swinderen B. van, Weible M.W. \& Brownlie J.C. 2015. Wolbachia influences the production of octopamine and affects Drosophila male aggression. Appl Env. Microbiol. AEM.00573-15.

Ross P.A., Turelli M. \& Hoffmann A.A. 2019. Evolutionary Ecology of Wolbachia Releases for Disease Control. Annu. Rev. Genet. 53: 93-116. 
Rousset F., Raymond M. \& Kjellberg F. 1991. Cytoplasmic incompatibilities in the mosquito Culex pipiens: How to explain a cytotype polymorphism?*. J. Evol. Biol. 4: 69-81.

Rousset F. \& Solignac M. 1995. Evolution of single and double Wolbachia symbioses during speciation in the Drosophila simulans complex. Proc. Natl. Acad. Sci. 92: 6389-6393.

Rousset F., Vautrin D. \& Solignac M. 1992. Molecular identification of Wolbachia, the agent of cytoplasmic incompatibility in Drosophila simulans, and variability in relation with host mitochondrial types. Proc. R. Soc. Lond. B Biol. Sci. 247: 163-168.

Rowley S.M., Raven R.J. \& McGraw E.A. 2004. Wolbachia pipientis in Australian Spiders. Curr. Microbiol. 49: 208-214.

Russell J.A. 2012. The ants (Hymenoptera: Formicidae) are unique and enigmatic hosts of prevalent Wolbachia (Alphaproteobacteria) symbionts. Myrmecol. News. 16: 18 .

Russell J.A., Goldman-Huertas B., Moreau C.S., Baldo L., Stahlhut J.K., Werren J.H. \& Pierce N.E. 2009. Specialization and geographic isolation among wolbachia symbionts from ants and lycaenid butterflies. Evolution. 63: 624-640.

Sabelis Maurice W. 1992. Predatory Arthropods. In: Crawley M.J. (eds), Natural Enemies: The Population Biology of Predators, Parasites and Diseases, Blackwell Scientific Publications,

Sahoo R.K., Lohman D.J., Wahlberg N., Müller C.J., Brattström O., Collins S.C., Peggie D., Aduse-Poku K. \& Kodandaramaiah U. 2018. Evolution of Hypolimnas butterflies (Nymphalidae): Out-of-Africa origin and Wolbachiamediated introgression. Mol. Phylogenet. Evol. 123: 50-58.

Salt G. \& Salt 1970. The Cellular Defence Reactions of Insects. Cambridge University Press, 140 pp. 
Salunkhe R.C., Narkhede K.P. \& Shouche Y.S. 2014. Distribution and Evolutionary Impact of Wolbachia on Butterfly Hosts. Indian J. Microbiol. 54: 249-254.

Sanaei E., Husemann M., Seiedy M., Rethwisch M., Tuda M., Toshova T.B., Kim M.J., Atanasova D. \& Kim I. 2019. Global genetic diversity, lineage distribution, and Wolbachia infection of the alfalfa weevil Hypera postica (Coleoptera: Curculionidae). Ecol. Evol. 9: 9546-9563.

Sapountzis P., Zhukova M., Hansen L.H., Sørensen S.J., Schiøtt M. \& Boomsma J.J. 2015. Acromyrmex leaf-cutting ants have simple gut microbiota with nitrogen-fixing potential. Appl Env. Microbiol. AEM.00961-15.

Sasaki T., Kubo T. \& Ishikawa H. 2002. Interspecific Transfer of Wolbachia Between Two Lepidopteran Insects Expressing Cytoplasmic Incompatibility: A Wolbachia Variant Naturally Infecting Cadra cautella Causes Male Killing in Ephestia kuehniella. Genetics. 162: 1313-1319.

Schilthuizen M.O. \& Stouthamer R. 1997. Horizontal transmission of parthenogenesis-inducing microbes in Trichogramma wasps. Proc. R. Soc. Lond. B Biol. Sci. 264: 361-366.

Schmidt T.L., Barton N.H., Rašić G., Turley A.P., Montgomery B.L., IturbeOrmaetxe I., Cook P.E., Ryan P.A., Ritchie S.A., Hoffmann A.A., O’Neill S.L. \& Turelli M. 2017. Local introduction and heterogeneous spatial spread of dengue-suppressing Wolbachia through an urban population of Aedes aegypti. PLOS Biol. 15: e2001894.

Sheehan K.B., Martin M., Lesser C.F., Isberg R.R. \& Newton I.L.G. 2016. Identification and Characterization of a Candidate Wolbachia pipientis Type IV Effector That Interacts with the Actin Cytoskeleton. mBio. 7: e00622-16.

Shoemaker D.D., Machado C.A., Molbo D., Werren J.H., Windsor D.M. \& Herre E.A. 2002. The distribution of Wolbachia in fig wasps: correlations with host phylogeny, ecology and population structure. Proc. R. Soc. Lond. B Biol. Sci. 269: 2257-2267. 
Sicard M., Bonneau M. \& Weill M. 2019. Wolbachia prevalence, diversity, and ability to induce cytoplasmic incompatibility in mosquitoes. Curr. Opin. Insect Sci. 34: 12-20.

Sicard M., Dittmer J., Grève P., Bouchon D. \& Braquart-Varnier C. 2014. A host as an ecosystem: Wolbachia coping with environmental constraints. Environ. Microbiol. 16: 3583-3607.

da Silva Gonçalves D., Iturbe-Ormaetxe I., Martins-da-Silva A., Telleria E.L., Rocha M.N., Traub-Csekö Y.M., O’Neill S.L., Sant’Anna M.R.V. \& Moreira L.A. 2019. Wolbachia introduction into Lutzomyia longipalpis (Diptera:

Psychodidae) cell lines and its effects on immune-related gene expression and interaction with Leishmania infantum. Parasit. Vectors. 12: 33.

Sintupachee S., Milne J.R., Poonchaisri S., Baimai V. \& Kittayapong P. 2006. Closely related Wolbachia strains within the pumpkin arthropod community and the potential for horizontal transmission via the plant. Microb. Ecol. 51: 294-301.

Sironi M., Bandi C., Sacchi L., Di B.S., Damiani G. \& Genchi C. 1995. Molecular evidence for a close relative of the arthropod endosymbiont Wolbachia in a filarial worm. Mol. Biochem. Parasitol. 74: 223-227.

Stahlhut J.K., Desjardins C.A., Clark M.E., Baldo L., Russell J.A., Werren J.H. \& Jaenike J. 2010. The mushroom habitat as an ecological arena for global exchange of Wolbachia. Mol. Ecol. 19: 1940-1952.

Stouthamer R., Breeuwer J.A. \& Hurst G.D. 1999. Wolbachia pipientis: microbial manipulator of arthropod reproduction. Annu. Rev. Microbiol. 53: 71-102.

Su Q., Hu G., Yun Y. \& Peng Y. 2019. Horizontal transmission of Wolbachia in Hylyphantes graminicola is more likely via intraspecies than interspecies transfer. Symbiosis. 79: 123-128.

Taylor M.J., Bandi C. \& Hoerauf A. 2005. Wolbachia.Bacterial Endosymbionts of Filarial Nematodes. pp. 245-284. In: Baker J.R., Muller R., \& Rollinson D. (eds), Advances in Parasitology, Academic Press, 
Teixeira L., Ferreira Á. \& Ashburner M. 2008. The Bacterial Symbiont Wolbachia Induces Resistance to RNA Viral Infections in Drosophila melanogaster. PLOS Biol. 6: e1000002.

Telschow A., Hammerstein P., Werren J.H. \& Gavrilets S. 2005. The effect of wolbachia versus genetic incompatibilities on reinforcement and speciation. Evolution. 59: 1607-1619.

Terra W.R. 1990. Evolution of Digestive Systems of Insects. Annu. Rev. Entomol. 35: 181-200.

Terra W.R. \& Ferreira C. 2012. 11 - Biochemistry and Molecular Biology of Digestion. pp. 365-418. In: Gilbert L.I. (eds), Insect Molecular Biology and Biochemistry, Academic Press, San Diego.

Thompson J.N. 1987. Symbiont-induced speciation. Biol. J. Linn. Soc. 32: 385-393.

Thrall P.H., Hochberg M.E., Burdon J.J. \& Bever J.D. 2007. Coevolution of symbiotic mutualists and parasites in a community context. Trends Ecol. Evol. 22: $120-126$.

Tinsley M.C. \& Majerus M.E. 2007. Small steps or giant leaps for male-killers? Phylogenetic constraints to male-killer host shifts. BMC Evol. Biol. 7: 238.

Toju H. \& Fukatsu T. 2011. Diversity and infection prevalence of endosymbionts in natural populations of the chestnut weevil: relevance of local climate and host plants. Mol. Ecol. 20: 853-868.

Tolley S.J.A., Nonacs P. \& Sapountzis P. 2019. Wolbachia Horizontal Transmission Events in Ants: What Do We Know and What Can We Learn?. Front. Microbiol. 10: 296.

Toomey M.E., Panaram K., Fast E.M., Beatty C. \& Frydman H.M. 2013. Evolutionarily conserved Wolbachia-encoded factors control pattern of stemcell niche tropism in Drosophila ovaries and favor infection. Proc. Natl. Acad. Sci. 201301524. 
Townson H. 2002. Wolbachia as a potential tool for suppressing filarial transmission. Ann. Trop. Med. Parasitol. 96 Suppl 2: S117-27.

Truitt A.M., Kapun M., Kaur R. \& Miller W.J. 2018. Wolbachia modifies thermal preference in Drosophila melanogaster. Environ. Microbiol. 21: 3259-3268.

Tseng S.-P., Hsu P.-W., Lee C.-C., Wetterer J.K., Hugel S., Wu L.-H., Lee C.-Y., Yoshimura T. \& Yang C.-C.S. 2020. Evidence for Common Horizontal Transmission of Wolbachia among Ants and Ant Crickets: Kleptoparasitism Added to the List. Microorganisms. 8: 805.

Turelli M. 1994. Evolution of Incompatibility-Inducing Microbes and Their Hosts. Evolution. 48: 1500-1513.

Turelli M. \& Barton N.H. 2017. Deploying dengue-suppressing Wolbachia : Robust models predict slow but effective spatial spread in Aedes aegypti. Theor. Popul. Biol. 115: 45-60.

Turelli M., Cooper B.S., Richardson K.M., Ginsberg P.S., Peckenpaugh B., Antelope C.X., Kim K.J., May M.R., Abrieux A., Wilson D.A., Bronski M.J., Moore B.R., Gao J.-J., Eisen M.B., Chiu J.C., Conner W.R. \& Hoffmann A.A. 2018. Rapid Global Spread of wRi-like Wolbachia across Multiple Drosophila. Curr. Biol. 28: 963-971.e8.

Turelli M. \& Hoffmann A.A. 1995. Cytoplasmic incompatibility in Drosophila simulans: dynamics and parameter estimates from natural populations. Genetics. 140: 1319-1338.

Unckless R.L., Boelio L.M., Herren J.K. \& Jaenike J. 2009. Wolbachia as populations within individual insects: causes and consequences of density variation in natural populations. Proc. R. Soc. B Biol. Sci. 276: 2805-2811.

Vavre F. \& Charlat S. 2012. Making (good) use of Wolbachia: what the models say. Curr. Opin. Microbiol. 15: 263-268. 
Vavre F., Fleury F., Lepetit D., Fouillet P. \& Boulétreau M. 1999. Phylogenetic evidence for horizontal transmission of Wolbachia in host-parasitoid associations. Mol. Biol. Evol. 16: 1711-1723.

Vavre F., Fouillet P. \& Leury F. 2003. Between- and Within-Host Species Selection on Cytoplasmic Incompatibility-Inducing Wolbachia in Haplodiploids. Evolution. 57: 421-427.

Veneti Z., Zabalou S., Papafotiou G., Paraskevopoulos C., Pattas S., Livadaras I., Markakis G., Herren J.K., Jaenike J. \& Bourtzis K. 2012. Loss of reproductive parasitism following transfer of male-killing Wolbachia to Drosophila melanogaster and Drosophila simulans. Heredity. 109: 306-312.

Versace E., Nolte V., Pandey R.V., Tobler R. \& Schlötterer C. 2014. Experimental evolution reveals habitat-specific fitness dynamics among Wolbachia clades in Drosophila melanogaster. Mol. Ecol. 23: 802-814.

de Vienne D.M., Refrégier G., López-Villavicencio M., Tellier A., Hood M.E. \& Giraud T. 2013. Cospeciation vs host-shift speciation: methods for testing, evidence from natural associations and relation to coevolution. New Phytol. 198: $347-385$.

Vorburger C. \& Perlman S.J. 2018. The role of defensive symbionts in host-parasite coevolution. Biol. Rev. 93: 1747-1764.

Wang Z., Deng C., Yun Y., Jian C. \& Peng Y. 2010. Molecular detection and the phylogenetics of Wolbachia in Chinese spiders (Araneae). J. Arachnol. 38: $237-241$.

Waxman D., Weinert L.A. \& Welch J.J. 2014. Inferring Host Range Dynamics from Comparative Data: The Protozoan Parasites of New World Monkeys. Am. Nat. 184: 65-74.

Weeks A.R., Turelli M., Harcombe W.R., Reynolds K.T. \& Hoffmann A.A. 2007. From Parasite to Mutualist: Rapid Evolution of Wolbachia in Natural Populations of Drosophila. PLOS Biol. 5: e114. 
Weeks A.R., Velten R. \& Stouthamer R. 2003. Incidence of a new sex-ratiodistorting endosymbiotic bacterium among arthropods. Proc. R. Soc. Lond. B Biol. Sci. 270: 1857-1865.

Weinert L.A., Araujo-Jnr E.V., Ahmed M.Z. \& Welch J.J. 2015. The incidence of bacterial endosymbionts in terrestrial arthropods. Proc. R. Soc. B Biol. Sci. 282: 20150249.

Werren J.H. 1997. Biology of wolbachia. Annu. Rev. Entomol. 42: 587-609.

Werren J.H., Baldo L. \& Clark M.E. 2008. Wolbachia: master manipulators of invertebrate biology. Nat. Rev. Microbiol. 6: 741.

Werren J.H. \& Bartos J.D. 2001. Recombination in Wolbachia. Curr. Biol. 11: 431435.

Werren J.H. \& Windsor D.M. 2000. Wolbachia infection frequencies in insects: evidence of a global equilibrium?. Proc. R. Soc. Lond. B Biol. Sci. 267: 12771285.

Werren J.H., Zhang W. \& Guo L.R. 1995. Evolution and phylogeny of Wolbachia: reproductive parasites of arthropods. Proc R Soc Lond B. 261: 55-63.

White P.M., Pietri J.E., Debec A., Russell S., Patel B. \& Sullivan W. 2017. Mechanisms of Horizontal Cell-to-Cell Transfer of Wolbachia spp. in Drosophila melanogaster. Appl. Environ. Microbiol. 83: e03425-16.

Williams G.C. 1992. Natural Selection: Domains, Levels, and Challenges. Oxford University Press, 219 pp.

Wilmes M., Meier K., Schiefer A., Josten M., Otten C.F., Klöckner A., Henrichfreise B., Vollmer W., Hoerauf A. \& Pfarr K. 2017. AmiD Is a Novel Peptidoglycan Amidase in Wolbachia Endosymbionts of Drosophila melanogaster. Front. Cell. Infect. Microbiol. 7: 353.

Wiwatanaratanabutr I. \& Zhang C. 2016. Wolbachia infections in mosquitoes and their predators inhabiting rice field communities in Thailand and China. Acta Trop. 159: 153-160. 
Woodhams D.C., Bletz M.C., Becker C.G., Bender H.A., Buitrago-Rosas D., Diebboll H., Huynh R., Kearns P.J., Kueneman J., Kurosawa E., LaBumbard B.C., Lyons C., McNally K., Schliep K., Shankar N., Tokash-Peters A.G., Vences M. \& Whetstone R. 2020. Host-associated microbiomes are predicted by immune system complexity and climate. Genome Biol. 21: 23.

Woolhouse M.E.J., Haydon D.T. \& Antia R. 2005. Emerging pathogens: the epidemiology and evolution of species jumps. Trends Ecol. Evol. 20: 238244.

Xi Z., Khoo C.C.H. \& Dobson S.L. 2005. Wolbachia Establishment and Invasion in an Aedes aegypti Laboratory Population. Science. 310: 326-328.

Xie K., Lu Y.-J., Yang K., Huo S.-M. \& Hong X.-Y. 2019. Co-infection of Wolbachia and Spiroplasma in spider mite Tetranychus truncatus increases male fitness. Insect Sci. 00: 1-17.

Yang C.-Y., Xiao J.-H., Niu L.-M., Ma G.-C., Cook J.M., Bian S.-N., Fu Y.-G. \& Huang D.-W. 2012. Chaos of Wolbachia Sequences Inside the Compact Fig Syconia of Ficus benjamina (Ficus: Moraceae). PLoS ONE. 7: .

Yang X.-H., Zhu D.-H., Liu Z., Zhao L. \& Su C.-Y. 2013. High Levels of Multiple Infections, Recombination and Horizontal Transmission of Wolbachia in the Andricus mukaigawae (Hymenoptera; Cynipidae) Communities. PLoS ONE. 8: $1-11$.

Ye Y.H., Seleznev A., Flores H.A., Woolfit M. \& McGraw E.A. 2017. Gut microbiota in Drosophila melanogaster interacts with Wolbachia but does not contribute to Wolbachia-mediated antiviral protection. J. Invertebr. Pathol. 143: $18-25$.

Yen J.H. \& Barr A.R. 1971. New hypothesis of the cause of cytoplasmic incompatibility in Culex pipiens L. Nature. 232: 657-658.

Yen P.-S. \& Failloux A.-B. 2020. A Review: Wolbachia-Based Population Replacement for Mosquito Control Shares Common Points with Genetically Modified Control Approaches. Pathogens. 9: . 
Yun Y., Peng Y., Liu F.X. \& Lei C. 2011. Wolbachia screening in spiders and assessment of horizontal transmission between predator and prey. Neotrop. Entomol. 40: 164-169.

Zabalou S., Riegler M., Theodorakopoulou M., Stauffer C., Savakis C. \& Bourtzis K. 2004. Wolbachia-induced cytoplasmic incompatibility as a means for insect pest population control. Proc. Natl. Acad. Sci. 101: 15042-15045.

Zaidman-Rémy A., Hervé M., Poidevin M., Pili-Floury S., Kim M.-S., Blanot D., Oh B.-H., Ueda R., Mengin-Lecreulx D. \& Lemaitre B. 2006. The Drosophila Amidase PGRP-LB Modulates the Immune Response to Bacterial Infection. Immunity. 24: 463-473.

Zhang B., Leonard S.P., Li Y. \& Moran N.A. 2019. Obligate bacterial endosymbionts limit thermal tolerance of insect host species. Proc. Natl. Acad. Sci. 116: 24712-24718.

Zhu L.-Y., Zhang K.-J., Zhang Y.-K., Ge C., Gotoh T. \& Hong X.-Y. 2012. Wolbachia Strengthens Cardinium-Induced Cytoplasmic Incompatibility in the Spider Mite Tetranychus piercei McGregor. Curr. Microbiol. 65: 516-523.

Zhu Y.-X., Song Y.-L., Zhang Y.-K., Hoffmann A.A., Zhou J.-C., Sun J.-T. \& Hong X.-Y. 2018. Incidence of facultative bacterial endosymbionts in spider mites associated with local environment and host plant. Appl Env. Microbiol. AEM.02546-17.

Zorić L.Š., Ståhls G. \& Đan M. 2019. First record of the bacterial endosymbiont Wolbachia for phytophagous hoverflies from genus Merodon (Diptera: Syrphidae). Entomol. Sci. 22: 283-296.

Zouache K., Voronin D., Tran-Van V., Mousson L., Failloux A.-B. \& Mavingui P. 2009. Persistent Wolbachia and Cultivable Bacteria Infection in the Reproductive and Somatic Tissues of the Mosquito Vector Aedes albopictus. PLOS ONE. 4: e6388. 
Zug R. \& Hammerstein P. 2012. Still a host of hosts for Wolbachia: analysis of recent data suggests that $40 \%$ of terrestrial arthropod species are infected. PloS One. 7: e38544.

Zug R. \& Hammerstein P. 2014. Bad guys turned nice? A critical assessment of Wolbachia mutualisms in arthropod hosts. Biol. Rev. 90: 89-111.

Zug R. \& Hammerstein P. 2015. Wolbachia and the insect immune system: what reactive oxygen species can tell us about the mechanisms of Wolbachia-host interactions. Front. Microbiol. 6: 1201.

Zug R. \& Hammerstein P. 2018. Evolution of reproductive parasites with direct fitness benefits. Heredity. 120: 266-281.

Zug R., Koehncke A. \& Hammerstein P. 2012. Epidemiology in evolutionary time: the case of Wolbachia horizontal transmission between arthropod host species. J. Evol. Biol. 25: 2149-2160. 